$\frac{10}{815}-95 y+0$

DOE/MT/92010-10

3 (DE95000176)

\title{
WETLAND TREATMENT OF
}

OIL AND GAS WELL WASTE WATERS

Final Report

By

R. Kadlec

K. Srinivasan

August 1995

Performed Under Contract No. DE-AC22-92MT92010

University of Michigan

Ann Arbor, Michigan

\section{Bartlesville Project Office \\ U. S. DEPARTMENT OF ENERGY Bartlesville, Oklahoma}




\section{DISCLAIMER}

This report was prepared as an account of work sponsored by an agency of the United States Government. Neither the United States Government nor any agency thereof, nor any of their employees, makes any warranty, expressed or implied, or assumes any legal liability or responsibility for the accuracy, completeness, or usefulness of any information, apparatus, product, or process disclosed, or represents that its use would not infringe privately owned rights. Reference herein to any specific commercial product, process, or service by trade name, trademark, manufacturer, or otherwise does not necessarily constitute or imply its endorsement, recommendation, or favoring by the United States Government or any agency thereof. The views and opinions of authors expressed herein do not necessarily state or reflect those of the United States Government.

This report has been reproduced directly from the best available copy.

Available to DOE and DOE contractors from the Office of Scientific and Technical Information, P.O. Box 62, Oak Ridge, TN 37831; prices available from (615) 5768401 .

Available to the public from the National Technical Information Service, U.S. Department of Commerce, 5285 Port Royal Rd., Springfield VA 22161 


\section{DISCLAIMER}

Portions of this document may be illegible in electronic image products. Images are produced from the best available original document. 


\title{
Wetland Treatment of Oil and Gas \\ Well Waste Waters
}

Final Report

By

R. Kadlec

and

K. Srinivasan

August 1995

Work Performed Under Contract No. DE-AC22-92MT92010

\author{
Prepared for \\ U.S. Department of Energy \\ Assistant Secretary for Fossil Energy
}

\author{
Brent Smith, Project Manager \\ Metairie Site Office \\ 900 Commerce Road, East \\ New Orleans, LA 70123
}

Prepared by

The University of Michigan

2300 Hayward

Ann Arbor, MI 48109-2136

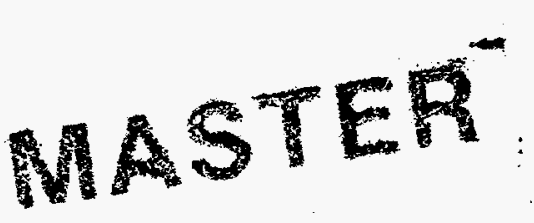

DISTRIBUTION OF THIS DOCUMENT IS UNLIMITED

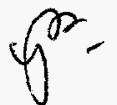





\section{TABLE OF CONTENIS}

Title page $\quad$ i

List of Figures $\quad$ iv

List of Tables $\quad v$

Abstract vi

$\begin{array}{ll}\text { Executive Summary } & 1\end{array}$

A. Wetlands: Overview 1

B. Tasks 1

C. Accomplishments 2

$\begin{array}{ll}\text { Introduction } & 7\end{array}$

Wetlands: A Chemical Engineering Description 7

Project Description $\quad 7$

$\begin{array}{lr}\text { Accomplishments } & 9\end{array}$

Task 1: Literature Review 9

Task 2: Construction of a Laboratory-scale Wetland (LWs) 9

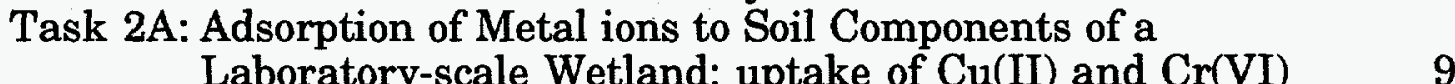

Task 2B: Development of Wetland Amendments 12

Task 2B: Development of wetland Amendments: Algae 17

Task 3: Dynamics of the Uptake and the Fate of Toxic Organics

Task 3A: Dynamics of the Uptake of Heavy Metals singly and in non-stoichiometric Combination by Laboratory-type Wetlands (LWs)

Task 4: Design of a Field-scale Wetland System 36

Acknowledgments $\quad 47$

$\begin{array}{ll}\text { Bibliography } & 48\end{array}$

Index $\quad 51$

Appendix I 


\section{List of Figures}

Figure 1 A Schematic of a Typical Wetland 2

Figure 2 A Chemical Engineering Approach to Wetlands 3

Figure $3 \quad$ Uptake of $\mathrm{Cu}$ (II) by Wetland Soils 11

Figure 4 Adsorption of $\mathrm{Cr}(\mathrm{VI})$ by Wetland Soils 11

Figure 5 Preparation Scheme of Clay-CBDA-DT Complex 13

Figure 6 Proposed Mechanism for the Adsorption of cationic Metal ions onto Clay-Surfactant Complex

$\begin{array}{lll}\text { Figure } 7 & \text { Adsorption of Cd ions onto Algal Cells } & 18\end{array}$

Figure $8 \quad$ Phenol Calibration Curve 22

Figure 9 Comparison of Phenol Assay before and after Steam Distillation $\quad 22$

Figure $10 \quad$ Uptake of Phenol by LWs: Initial Concentration - 100 ppm 23

Figure 11 Uptake of $\beta$-naphthoic Acid by LWs: initial Concentration $10 \mathrm{ppm}$

Figure 12 Modeling the Fate of Phenol in LWs: Zero Order Disappearance Kinetics: Low Initial Phenol Concentration

Figure 13 Modeling the Fate of Phenol in LWs: First Order Disappearance Kinetics: High Initial Phenol Concentration

Figure 14 Dynamics of Cu(II) Uptake by LWs: Effect of Added Peat 30

Figure 15 The Fate of $\mathrm{Cr}(\mathrm{VI})$ in LWs: With and Without Added Peat 30

Figure 16 Removal of $\mathrm{Cr}(\mathrm{VI})$ by LWs in Presence of $\mathrm{Cu}(\mathrm{II})$ ions: Effect of $\mathrm{Cu} / \mathrm{Cr}$ Ratio

Figure 17 Removal of $\mathrm{Cu}$ (II) Ions by LWs in Presence of Cr(VI): Effect of $\mathrm{Cu} / \mathrm{Cr}$ Ratio 


\section{List of Tables}

Table 1 Properties of Modified-clays

Table 2 Adsorption of $\beta$-naphthoic Acid by Wetland Soils and

Modified-Clays: Langmuir Constants as a Function of $\mathrm{pH}$

Table 3 Assay of Phenol and $\beta$-naphthoic Acid

20

Table 4 Effect of System Variables on Phenol Uptake by LWs:

21

Table 5 Calculated and Input Model Parameters for Phenol

Disappearance in LWs

Table 6 Details of Experimental Conditions

31

Table $7 \quad$ Kinetic Constants for Cr(VI) Uptake by LWs

in Presence of $\mathrm{Cu}$ (II)

32

Table 8 Constants for $\mathrm{Cu}(\mathrm{II})$ Uptake by LWs in Presence of $\mathrm{Cr}(\mathrm{VI})$

34 


\section{Abstract}

Constructed wetlands are small, on-site systems that possess three of the most desirable components of an industrial waste water treatment scheme: low cost, low maintenance and upset resistance. The main objective of the present study is to extend the knowledge base of wetland treatment systems to include processes and substances of particular importance to small, on-site systems receiving oil and gas well wastewaters.

A list of the most relevant and comprehensive publications on the design of wetlands for water quality improvement was compiled and critically reviewed. Based on our literature search and conversations with researchers in the private sector, toxic organics such as phenolics and b-naphthoic acid, (NA), and metals such as $\mathrm{Cu}(\mathrm{II})$ and $\mathrm{Cr}(\mathrm{VI})$ were selected as target adsorbates.

A total of 90 lysimeters equivalent to a laboratory-scale wetland were designed and built to monitor the uptake and transformation of toxic organics and the immobilization of metal ions.

Smectitic clays (hectorite and montmorillonite) modified by alkyl diamine-type and quaternary ammonium-type surfactants were shown to adsorb strongly metal ions ( $\mathrm{Cu}$ (II) and $\mathrm{Cr}$ (VI) ) and toxic organics such as b-naphthoic acid (NA). The surfactant-modified clays are expected to act as inexpensive additives to a wetland to enhance its sorption potential for a number of pollutants, organic and inorganic. Similarly, metal uptake studies with unicellular green alga, Chlorella vulgaris, were undertaken to evaluate the ability of algae to enhance the metal uptake potential of wetlands. It was shown that Chlorella vulgaris was a potent adsorbent for $\mathrm{Cd}$ (II) ions from aqueous media.

Studies on the uptake of toxic organics such as phenol and b-naphthoic acid (NA) and heavy metals such as $\mathrm{Cu}(\mathrm{II})$ and $\mathrm{Cr}(\mathrm{VI})$, the latter two singly or as nonstoichiometric mixtures by laboratory-type wetlands ( LWs) were conducted. These LWs were designed and built during the first year of this study.

The uptake of phenol by the wetlands was found to be quite rapid, and nearly complete in 50 hours, but it was also observed that there was a small, but measurable evaporative loss of phenol from the supernatant water during the same time period, especially during Summer months. A lower water depth in LWs resulted in a slightly higher evaporative loss of phenol, but the major removal mechanism of phenol was shown to be sorption to various components of a LW and degradation by its microbial constituents. Phenol sorption by LWs was enhanced by the addition of peat.

A mass balance model was developed to quantify the fate of phenol in LWs. It was assumed that the fate of phenol in LWs is determined by evaporation of the solute and the solvent, adsorption of phenol onto various components of $L W$ and its biodegradation, both in solution and at solid-liquid interface. Both zero order and 
first order kinetics for the overall disappearance of phenol fitted the experimental data. Evaporative loss of water appeared to be more important than the loss of phenol through evaporation.

$\beta$-naphthoic acid (NA) sorbed quite slowly and there was no indication of evaporative losses in the case on NA.

The uptake of $\mathrm{Cu}$ (II) followed a tri-phasic behavior, attributed to partial hydrolysis and precipitation, sorption onto wetland components and a slow dispersion into underlying pore water of the LW. The addition of peat was observed to have only a minimal effect on $\mathrm{Cu}$ (II) immobilization by a LW. The uptake of $\mathrm{Cr}$ (VI) by laboratory-type wetland systems (LWs) appeared to be quite effective, and the addition of peat to the wetland produced only minor enhancement in $\mathrm{Cr}$ (VI) uptake.

The simultaneous uptake of $\mathrm{Cu}$ (II) and $\mathrm{Cr}$ (VI) by LWs from a binary mixture of the two ions was also studied. Non-stoichiometric mixtures of metal ions were used to minimize precipitation. The uptake of $\mathrm{Cr}(\mathrm{VI})$ in presence of $\mathrm{Cu}(\mathrm{II})$ by laboratory-type wetland systems (LWs) followed first order kinetics with an average half life of 25 hours irrespective of the initial $\mathrm{Cu} / \mathrm{Cr}$ ratio. On the other hand, $\mathrm{Cu}$ (II) removal was more complex with an average half life of only 3 hours.

A road map and guidelines for a field-scale implementation of a wetland system for the treatment of oil and gas wastewaters have been suggested. Two types of wetlands, surface flow (SF) and sub surface flow (SSF), have been considered, and the relative merits of each configuration have been reviewed. 


\section{Executive Summary}

\section{A. Wetlands: An Overview}

Constructed wetlands are small, on-site systems that possess three of the most desirable components of an industrial waste water treatment scheme: low cost, low maintenance and upset resistance. Operationally, a waste water stream is passed through shallow water containing an assemblage of emergent plants growing in organic soils (Figure 1). The organic soils and sediments possess a large and demonstrated sorption capacity for a wide variety of waterborne contaminants. Metals, such as copper, are held by cation exchange and specific adsorption processes $(1,2)$. Other pollutants, such as the agricultural chemical atrazine or the nutrient phosphorus, are bound by mechanisms, such as van der Waals binding $(3,4)$. Plant uptake contributes to the immobilization of some contaminants; ammonium nitrogen for example. Microbial degradation is quite effective in the wetland environment. Natural populations of microbes efficiently reduce nitrate to atmospheric nitrogen, for instance (5). The bacteria are found selectively on the submerged surfaces of soil, plant stems and leaves, and litter. Consequently, the very surfaces that are effective in sorbing contaminants are also the location of the bacteria which can cause degradation to non-toxic products. In other words, the wetland litter layer acts as a trickling filter and as an adsorption bed.

The construction of field-scale wetland systems should be based upon sensible design guidelines that enable treatment goals to be achieved economically. Two categories are used to classify constructed wetlands; surface flow wetlands (SF), and subsurface flow wetlands (SSF). Both attempt to duplicate natural systems with stands of soft stemmed emergent plants such as cattails (Typha spp.), reeds (Phragmites spp.), bulrush (Scirpus spp.), sedges (Carex spp.), and grasses. The two systems differ in that surface flow wetlands correspond to a water table above ground level, while subsurface flow wetlands correspond to a water table just below ground. Both types of wetland have the ability to treat polluted waters containing toxic organics and heavy metals from oil and gas well wastewaters.

\section{B. Tasks}

The purpose of this study is to extend the knowledge base for wetland treatment to include processes and substances of particular importance to small, on-site systems receiving oil and gas well wastewater. The specific project objectives are:

Task 1: Collection and critical evaluation of literature data on the sorption of heavy metals and the degradation of toxic organics commonly found in oil and gas waste waters by typical wetland soil and biological assemblages.

Task 2: Design and construction of a laboratory-type wetland system (LWs).

Task 2A: The measurement of the treatment potential of various components, such as the soil, of a wetland for the pollutants present in oil gas well wastewaters. 
Task 2B: Development of surfactant-modified clays and algal adsorption systems as additives to a constructed wetland to enhance the treatment potential for the specific pollutants in oil and gas well waste waters.

Tasks 3: Determine the dynamics of the uptake and the fate of toxic organics in laboratory-type wetlands (LWs).

Task 3A: Study the physico-chemical immobilization of heavy metals by LWs singly and in non-stoichiometric combinations.

Task 4: $\quad$ Suggest guidelines for the design of a full scale wetland system for field implementation to treat oil and gas well waste waters.

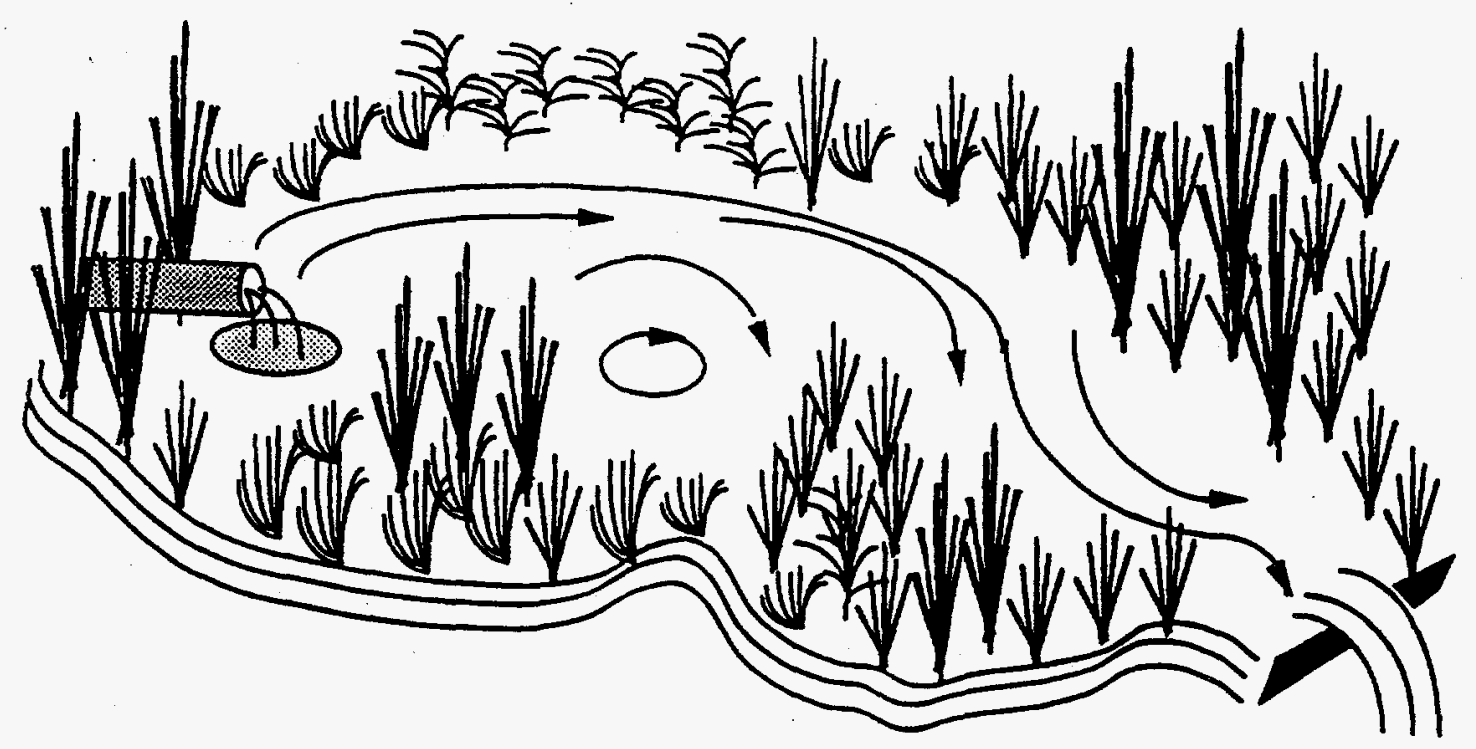

Figure 1. A schematic of a typical pond-and-island wetland. There are dead zones and preferential flow paths superimposed on the general flowthrough hydraulic pattern.

\section{Accomplishments}

In this report, an overview of a wetland treatment system and its increasing use in industrial waste water treatment has been presented. An idealized, reaction engineering description of wetlands, as shown in Figure 2, demonstrates how the various processes that occur in a wetland can be modeled. For example, it may be pointed out that the front end of a wetland can be visualized as a plug-flow reactor to take into account the delays in the breakthrough of contaminants. A series of completely mixed flow reactors (CMFRs) can be shown to represent an unit operation involving a multi-stage adsorption process. The mass transfer of solutes in a wetland is complicated by the occurrence of stagnant zones and the solute transport between these zones and the main flow channels occurs mostly by diffusion. This model of a wetland can be extended to describe an integrated treatment scheme that includes biodegradation of toxic organics in conjunction 
with the sorptive removal of heavy metals. During the early phases of the present project (Task 1), literature data on the use of wetlands for the treatment of oil and gas well wastewaters were compiled and critically evaluated (6). Further, our continued literature search (nominally completed under Task 1) and extensive conversations with expert researchers in the field unearthed more recent studies and a summary has been submitted to DOE in the second quarterly report (7). On the basis of above efforts, phenol and $\beta$-naphthoic acid and $\mathrm{Cu}$ (II) and $\mathrm{Cr}$ (VI) were selected as the primary organic and inorganic target adsorbates respectively of this study.

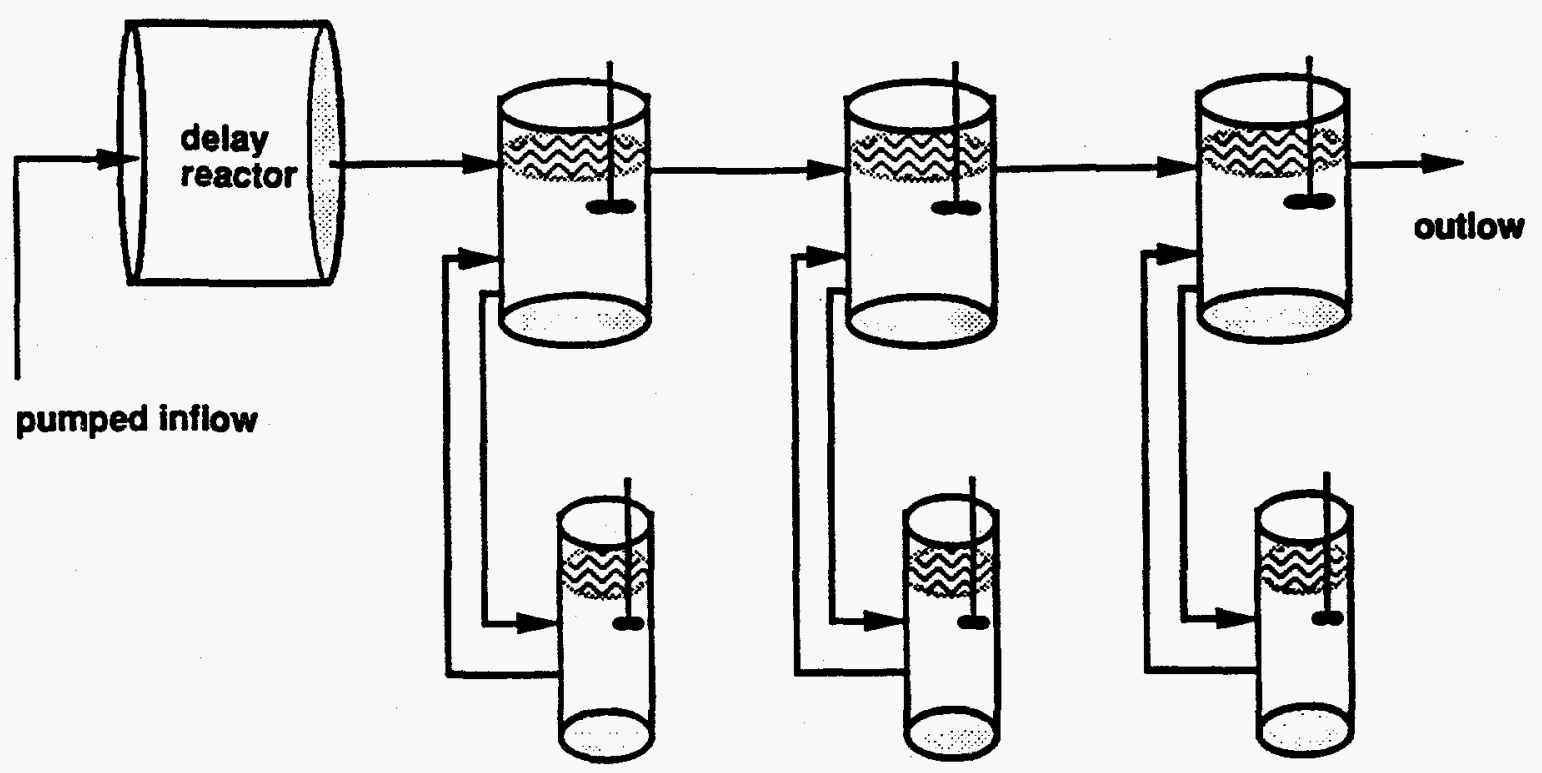

Figure 2. A chemical engineering approach to wetlands.

A laboratory-type wetland system was designed and built in the following manner: cattails (Typha latifolia) were grown in 50 liter lysimeters. A total of 90 lysimeters were constructed. Each lysimeter was filled with approximately 8 " to 12 " of wetland soil (obtained from an operating wetland in Michigan) and four cattails were planted per lysimeter. An indoor lighting system was designed and put in place in one of the laboratories of the Chemical Engineering Department at this University. The construction of lysimeters was undertaken so that cattails could be closely monitored and their environment carefully controlled. A 200 square $\mathrm{ft}$ area was illuminated by twelve 400 watt lights with an average light intensity of 1740 foot-candles. The area was sufficient to hold 80 microcosms or lysimeters. The remaining were housed in the Botanical Gardens at the University of Michigan. Due to problems in the growth of cattails, all the 90 lysimeters were later re-located at the Botanical Gardens till the end of the project period. 
Adsorption of heavy metals such as $\mathrm{Cu}$ (II) and $\mathrm{Cr}$ (VI) onto soils drawn from our laboratory-scale wetland revealed weak interaction even though the soils contained $12 \%$ by weight organic carbon (8). Subsequent studies showed that the above wetland soils were also weak adsorbents of toxic organics such as $\beta$ naphthoic acid $(9,10)$.

The use of potential wetland amendments such as modified-clays and algae was explored in detail. Two different types of surfactant-modified smectites were prepared. An alkyl diamine ( 1,3-alkyl diamino propane, DT) was used to modify smectites, hectorite and montmorillonite. In the first method, designated as the direct attachment method, the protonated form of DT was electrostatically attached to the negative sites of montmorillonite to produce MONT-DT. It was established that DT formed an "irreversibly" adsorbed coating on montmorillonite surface. In the second approach, hectorite was initially hydrophobed by the formation of a monolayer of a quaternary ammonium surfactant CBDA to yield hectorite-CBDA. In a second step, DT was anchored through its alkyl chain to hectorite-CBDA to form hectorite-CBDA-DT (HCDT). The surfactant coating was found to be quite stable. The surfactant weight percent of the two modified-clay adsorbents was assayed to be 47 and $51 \%$ respectively in the cases of HCDT and MONT-DT (11).

Adsorption of $\mathrm{Cu}(\mathrm{II}), \mathrm{Cr}$ (VI) and $\beta$-naphthoic acid (NA) onto HCDT and MONTDT have been carried out. $\mathrm{Cu}$ (II) is specifically adsorbed with very high affinity at $\mathrm{pH} 7.2$ to both the adsorbents and can be quantitatively desorbed at $\mathrm{pH} 3.0$, for example, $0.3 \mathrm{mmoles}$ of $\mathrm{Cu}(\mathrm{II}) / \mathrm{g}$ adsorbent is the limiting adsorption capacity at $\mathrm{pH} \mathrm{7.2}$ and the ratio of the affinity constants at the two $\mathrm{pH}$ is about 800 . Cr(VI) and NA have also been shown to bind strongly to the modified-clay surfaces as counterions, the optimal $\mathrm{pH}$ being 4.5. The limiting capacities for $\mathrm{Cr}(\mathrm{VI})$ and NA at $\mathrm{pH} 4.5$ are 2.3 and $0.8 \mathrm{mmoles} / \mathrm{g}$ respectively. Thus, we have been successful in developing a potential additive to wetland that is expected to augment the sorption potential of wetlands for heavy metals and toxic organics.

A green alga, Chlorella vulgaris, was also tried out as a potential additive to wetland. Initial studies with $\mathrm{Cd}(\mathrm{II})$ as the target metal ion showed a metal ion uptake of $0.25 \mathrm{~g} \mathrm{Cd}(\mathrm{II}) / \mathrm{g}$ dry weight of alga. However, in the case of $\mathrm{Cu}$ (II) and $\mathrm{Cr}(\mathrm{VI})$, the adsorption density was very low. Thus, a combination of algae and modified-clays, both inexpensive, have been shown to be potentially useful additives to a wetland treating oil and gas well waste waters.

The dynamics of the uptake and the fate of toxic organics such as phenol and $\beta$ naphthoic acid (NA) have been studied (12). The extent of physico-chemical immobilization of heavy metals such as $\mathrm{Cu}$ (II) and $\mathrm{Cr}$ (VI), singly or as nonstoichiometric mixtures, by laboratory-type wetlands (LWs), has been quantified. These LWs were designed and built during the first year of this study.

The uptake of phenol by the wetlands is quite rapid, and nearly complete in $\mathbf{5 0}$ hours, but it has also been found that there is a small, but measurable evaporative loss of phenol from the supernatant water during the same time period, especially during summer months. This result agrees with similar observations in the 
literature (13). A lower water depth results in slightly higher evaporative loss of phenol, but the major removal mechanism of phenol has been shown to be sorption to various components of a $\mathrm{LW}$ and degradation by its microbial constituents. Phenol reduction by LWs was moderately enhanced by the addition of peat (14).

A mass balance model has been developed to quantify the fate of phenol in LWs (15). It has been assumed that the fate of phenol in LWs is determined by evaporation of the solute and the solvent, adsorption of phenol onto various components of LW and its biodegradation, both in solution and at solid-liquid interface. Both zero order and first order kinetics for the overall disappearance of phenol appear to fit the experimental data. Evaporative loss of water appears to be more important than the loss of phenol through evaporation. $\beta$-naphthoic acid (NA) is sorbed quite slowly and there is no indication of evaporative losses in the case on NA.

The uptake of $\mathrm{Cu}$ (II) follows a tri-phasic behavior attributed to partial hydrolysis and precipitation, sorption onto wetland components and a slow dispersion into underlying pore water of the $\mathrm{LW}$. The addition of peat is observed to have only a minimal effect on $\mathrm{Cu}$ (II) immobilization by a $\mathrm{LW}$. The uptake of $\mathrm{Cr}$ (VI) by laboratory-type wetland systems (LWs) appears to be quite effective, and the addition of peat to the wetland produces only minor enhancement in $\mathrm{Cr}$ (VI) uptake.

The simultaneous uptake of $\mathrm{Cu}(\mathrm{II})$ and $\mathrm{Cr}(\mathrm{VI})$ by LWs from a binary mixture of the two ions has also been studied $(16,17)$. Non-stoichiometric mixtures of metal ions have been used to minimize precipitation. The uptake of $\mathrm{Cr}(\mathrm{VI})$ in presence of $\mathrm{Cu}$ (II) by laboratory-type wetland systems (LWs) follows first order kinetics with an average half life of 25 hours irrespective of the initial $\mathrm{Cu} / \mathrm{Cr}$ ratio. On the other hand, $\mathrm{Cu}$ (II) removal is more complex with an average half life of only 3 hours.

A road map and guidelines for the design of a field-scale wetland for the treatment of pollutants in oil and gas wastewaters has been developed.

The construction of field-scale wetland systems should be based upon sensible design guidelines that enable treatment goals to be achieved economically. Two categories are used to classify constructed wetlands; surface flow wetlands (SF), and subsurface flow wetlands (SSF). Both attempt to duplicate natural systems with stands of soft stemmed emergent plants such as cattails (Typha spp.), reeds (Phragmites spp.), bulrush (Scirpus spp.), sedges (Carex spp.), and grasses. The two systems differ in that surface flow wetlands correspond to a water table above ground level, while subsurface flow wetlands correspond to a water table just below ground level. The decision to construct a SSF treatment wetland is normally based upon two concerns; the need to avoid problems of exposure of humans and wildlife to the waters during treatment, and the need to reduce the vaporization of highly volatile compounds. Otherwise, both types of wetlands have the ability to treat polluted waters containing toxic organics and heavy metals from oil and gas wastewaters. In a wetland system, metals and toxicants are 
passed primarily from the sediments to the sediment-feeding birds and animals. The SSF wetland places these materials out of reach. An additional advantage of SSF systems is that having the water level below ground minimizes mosquito breeding potential.

The possible advantages of greater treatment efficiency of amended beds may not be sufficient to overcome the added cost of the media. However, the media can be chemically designed to add to the performance potential. For example, the DTmodified clays prepared in this study and green algae have been shown to be very effective against a number of toxic organics and cationic and anionic heavy metals and can be used to enhance the treatment potential of wetlands.

Design techniques are similar for SF and SSF systems. Sizing is the first step in the design process. The constants used should be gathered through experimentation, or from the literature. For most parameters, the values of the rate constants are not greatly different between SF wetlands and SSF wetlands. The gravel media of a SSF system is typically a large added cost compared to SF pricing, so SSF systems are generally more expensive. The additional cost may be justifiable in terms of ancillary considerations, such as mosquito production, human contact, and wildlife protection.

The compartmentalization and aspect ratios are set, with due attention to the hydraulic constraints and site constraints. The hydraulics are of greater concern for the SSF wetland, because a premium price is to be paid to keep water below ground. Loading and dimensional criteria must be met if flooding is not to occur, and dryout is to be avoided. To that end, the length to width ratio and media size are selected for the SSF wetland. For SF systems, structures are selected, a plant establishment strategy determined, and water conveyance is set.

The wetland project is then considered ready for a more detailed economic estimate, which may require techniques that acknowledge the features of wetland systems. 


\section{Introduction}

\section{Wetlands: A Chemical Engineering Description}

The purpose of the present study is to extend the knowledge base for wetland treatment to include processes and substances of particular importance to small, on-site systems receiving oil and gas well waste water. Collection of data on the sorption of heavy metals and the degradation of toxic organics commonly found in oil and gas waste waters by typical wetland soil and biological assemblages is one of the key tasks of this study. The field implementation, however, involves design questions, such as wetland configuration, waste water application rate, and the timing of intermittent discharges. These design considerations can be modeled using a reaction engineering approach to a wetland treatment scheme. Figure 2, as pointed out before, is an idealized, "flow sheet" representation of a typical SF constructed wetland.

The front end is visualized as a plug-flow reactor to take into account the delays in the breakthrough of contaminants. A series of completely mixed flow reactors (CMFRs) represents an unit operation involving a multi-stage adsorption process. The mass transfer of solutes in a wetland is complicated by the occurrence of stagnant zones and the solute transport between these zones and the main flow channels occurs mostly by diffusion. Thus, the distribution of toxics in the effluent stream is a complicated function of the residence times of the convective and diffusive processes and "tailing" of the effluent concentration profile has been observed. This model of a wetland can be extended to describe an integrated treatment scheme that includes biodegradation of toxic organics in conjunction with the sorptive removal of heavy metals.

\section{Project Description}

The following are the tasks that have been undertaken and completed to fulfill the goals of the present project.

Task 1: Collection and critical evaluation of literature data on the sorption of heavy metals and the degradation of toxic organics commonly found in oil and gas waste waters by typical wetland soil and biological assemblages.

Task 2: Design and construction of a laboratory-type wetland (LWs) system.

Task 2A: The measurement of the treatment potential of various components, such as the soil, of a wetland for the pollutants present in oil gas well waste waters.

Task 2B: Development of surfactant-modified clays and algal adsorption systems as additives to a constructed wetland to enhance the latter's treatment potential for specific pollutants in oil and gas well waste waters. 
Task 3: Evaluation of the potential of laboratory-type wetlands (LWs) for the sorptive degradation of phenol. Development of a quantitative model to quantify the fate of phenol in a $\mathrm{LW}$ environment. The extent of sorptive immobilization of $\beta$-naphthoic acid (NA) as a surrogate of ionogenic organic compounds.

Task 3B: Details of physico-chemical immobilization of heavy metals such as $\mathrm{Cu}(\mathrm{II})$ and $\mathrm{Cr}(\mathrm{VI})$ by Lws.

Task 4: $\quad$ Work on a preliminary design of a full scale wetland system for treating oil and gas well wastewaters.

- An information search of petroleum-related wetland projects was undertaken, and contacts were made to obtain recent results and advice on model compounds for our study. Amoco, British Petroleum, Chevron, and Marathon were the four oil companies that were approached for relevant data base and technical information. A list of key research articles and comprehensive reviews has been prepared. Phenol, $\beta$-naphthoic acid (NA), $\mathrm{Cu}(\mathrm{II})$, and $\mathrm{Cr}(\mathrm{VI})$ were selected as the target organic and inorganic adsorbates, respectively.

- Design and construction of a laboratory-scale wetland has been undertaken and completed.

- Two types of surfactant-modified smectitic clays have been developed as potential additives to a wetland treating oil and gas well waste waters. These modified clays are designated as hectorite-CBDA-DT (HCDT) and montmorillonite-DT (MONT-DT). These have been shown to adsorb NA, Cu(II), and $\mathrm{Cr}(\mathrm{VI})$ strongly.

- Green algae, Chlorella vulgaris, has also been considered as a potential additive to a wetland plant assemblage. Algae has been shown to adsorb cationic heavy metals such as Cd(II) strongly.

- The field implementation involves design questions, such as wetland configuration, waste water application rate, and the timing of intermittent discharges. These design considerations can be modeled using a reaction engineering approach in combination with actual data from a laboratory-type wetland ( $\mathrm{LW}$ ) system developed specifically for the immobilization of heavy metals and the sorption and degradation of toxic organics. Such a LW system has been built and data on the uptake of phenol, $\mathrm{Cu}(\mathrm{II})$, and $\mathrm{Cr}(\mathrm{VI})$ have been obtained. Furthermore, a mass balance model depicting the fate of phenol in LWs has been used to quantify experimental data and extract relevant kinetic parameters.

- A road map and guidelines for the design of a field-scale wetland have been suggested. 


\section{Accomplishments}

\section{Task 1: Literature Review}

A list of the most relevant and comprehensive publications ( 39 in all; listed in Appendix 1) on the design of wetlands for water quality improvement was compiled and critically reviewed. An information search unearthed four projects in the USA that currently use wetlands for the treatment of petroleum-related waste waters. Wetland Treatment systems for oil refinery waste waters exist at Mandan, North Dakota (Amoco Oil Company) and Richmond, California (Chevron Oil Corporation ). A vegetated submerged bed is being operated at Natchitoches, Louisiana by Tenneco for a similar end use. It is also known that British Petroleum has conducted research on wetlands and their interactions with petroleum-containing waste waters. In addition, a refinery in China has implemneted a full scale wetland as part of the wastewater treatment system. Preliminary conversations produced some guidance on selection of model compounds for our study, and indicated some possibility of data sharing from these private sector projects. A brief summary of information obtained through these efforts was submitted with the first quarterly report (also see refs 18-23). Based on our literature search and conversations with private sector projects, toxic organic compounds such as phenolics, and $\beta$-naphthoic acid and metals such as chromium (VI) and copper (II) were selected as the target pollutants.

Task 2: $\quad$ Construction of Laboratory-scale Wetlands (LWs)

A laboratory-type wetland system was designed and built and cattails (Typha latifolia ) were grown in 50 liter lysimeters. A total of 90 lysimeters were constructed. Each lysimeter was filled with approximately 8 " to 12 " of wetland soil (obtained from an operating wetland in Michigan) and four cattails were planted per lysimeter. An indoor lighting system was designed and put in place in one of the laboratories of the chemical engineering department at this University. The construction of lysimeters was undertaken so that cattails could be closely monitored and their environment carefully controlled. A 200 sq. $\mathrm{ft}$ area was illuminated by twelve 400 watt lights with an average light intensity of 1740 foot-candles. The area was sufficient to hold 80 microcosms or lysimeters. The remaining 10 are housed at the University of Michigan Botanical Gardens. Due to difficulties in the growth of LWs inside the building, all of the LWs were re-located to the Botanical Gardens of this university till the completion of the project. The maintenance of these LWs (in terms of trimming the cattails, adding water and fertilizer periodically ) was carried out by project personnel with help from the staff at the Botanical Gardens.

\section{Task 2A: Adsorption of Metal Ions to Soil Components of a Laboratory-scale Wetland: Uptake of $\mathrm{Cu}(\mathrm{II})$ and $\mathrm{Cr}(\mathrm{VI})$}

In the above paragraph we have described the construction and the maintenance of a laboratory-scale wetland. Before attempting to quantify the uptake of heavy metals and toxic organics by the entire microcosm, studies were initiated to 
examine the role of the (mineral) soil components of our wetland in such sorption processes.

A soil mass of $4.7 \mathrm{~g}$ wet soil was dispersed in de-ionized water to yield a soil slurry containing (on a wet basis) of $6.38 \mathrm{mg}$ wet soil $/ \mathrm{ml}$ slurry. The following are the properties of the soil used in the metal uptake study:

Moisture Content:

$46.7 \pm 2.3 \%$.

Organic Carbon Content:

$\mathrm{pH}$ of the soil slurry:

Ionic Strength:

$12.7 \pm 2.9 \%$ by weight ( on a dry weight basis).

$7.5-8.5$.

Not Determined

Equal volumes of soil slurry and metal solutions were mixed in a batch reactor and agitated for 40 hours. Solids were separated by centrifugation and the metals analyzed using Perkin-Elmer AS 3100 Flame AA spectrometer. Positive controls and blanks were included to account for losses, if any. All experiments were done in triplicates and the initial metal concentrations ranged (in both cases) from 1 $20 \mathrm{mg} / \mathrm{L}$. The results are shown in Figures 3 and 4 respectively for the case of $\mathrm{Cu}$ (II) and $\mathrm{Cr}$ (VI) adsorption. It is clear from the results shown in Figures 3 and 4 that these mineral wetland soils had very little capacity or affinity for adsorbing either of the metal ions. The upswing in $\mathrm{Cu}$ adsorption at the highest initial concentration used $(20 \mathrm{mg} / \mathrm{L})$ suggests that some of the $\mathrm{Cu}$ ions may have precipitated onto soil surface at the alkaline $\mathrm{pH}$ of the slurry. At the highest initial $\mathrm{Cu}$ concentration, the positive controls showed a significant loss of $\mathrm{Cu}$ ions from solution. For example, only $50 \%$ of the initial $\mathrm{Cu}(\mathrm{II})$ concentration $(20 \mathrm{mg} / \mathrm{L}$ ) was recovered in the supernatant after 40 hours of equilibration. This loss is attributed to possible hydrolysis and precipitation of $\mathrm{Cu}$ ions. These results seem to suggest that adsorption of cationic heavy metals such as $\mathrm{Cu}$ (II) by the soil component of a wetland is poor. Any uptake seems to involve hydrolysis and precipitation. This is in contrast to strong adsorption of $\mathrm{Cu}$ (II) ions to peat or modified clays $(1,11)$.

The uptake of $\mathrm{Cr}(\mathrm{VI})$, the anionic heavy metal, was also quite weak. This is not surprising in view of the well known fact that soil surfaces are invariably negatively charged. The positive controls showed a much smaller amount of loss from solution and it is concluded that $\mathrm{Cr}(\mathrm{VI})$ ions are poorly adsorbed due to exclusion from the soil/solution interface because of electrostatic repulsion between the soil surface and the anionic $\mathrm{Cr}$.

The uptake of $\beta$-naphthoic acid (NA) by soils was also measured at $\mathrm{pH} 7.5$, the natural $\mathrm{pH}$ of the soils, and at $\mathrm{pH} 4.5$, obtained by adding drops of $\mathrm{HCl}$ to soil slurry. It was observed that soils were poor adsorbents of (NA). These results are discussed in detail in the next section. 


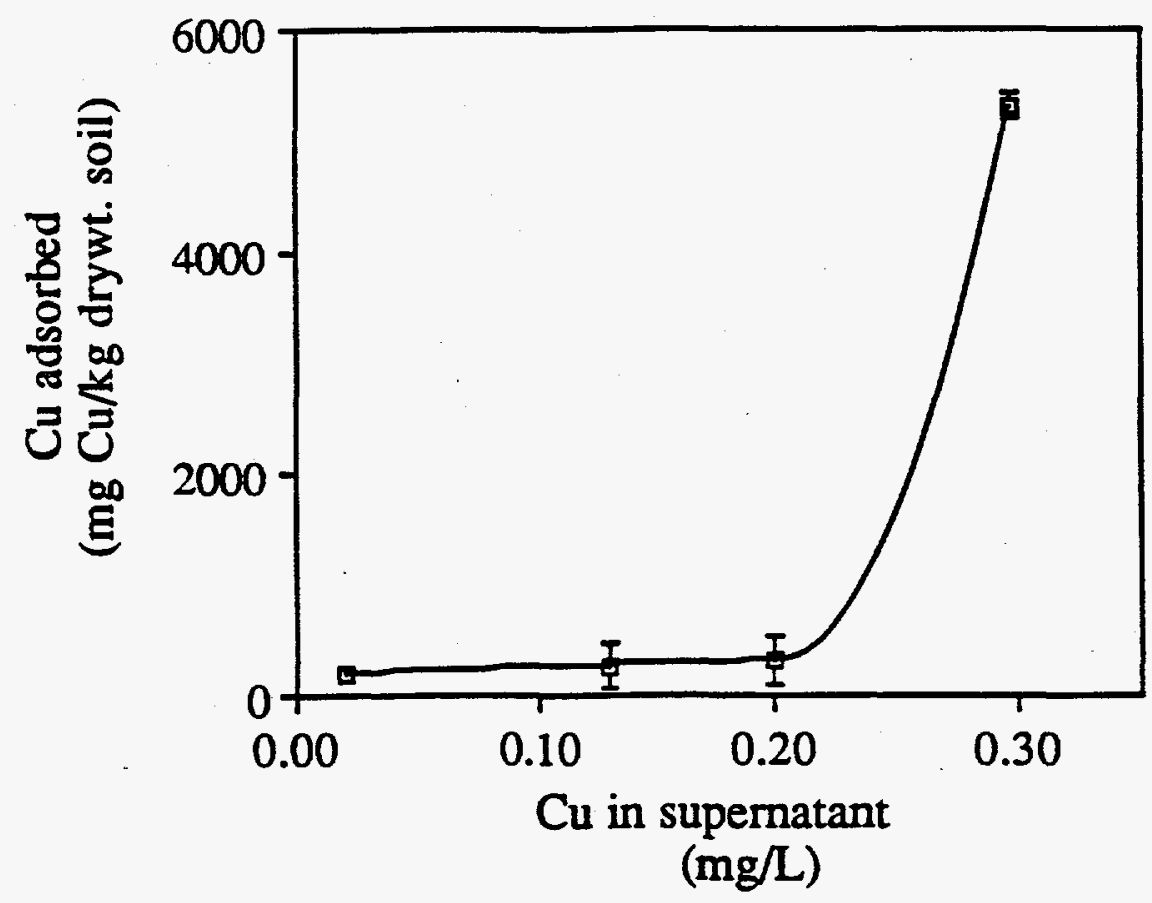

Figure 3. Copper adsorption by wetland soil.

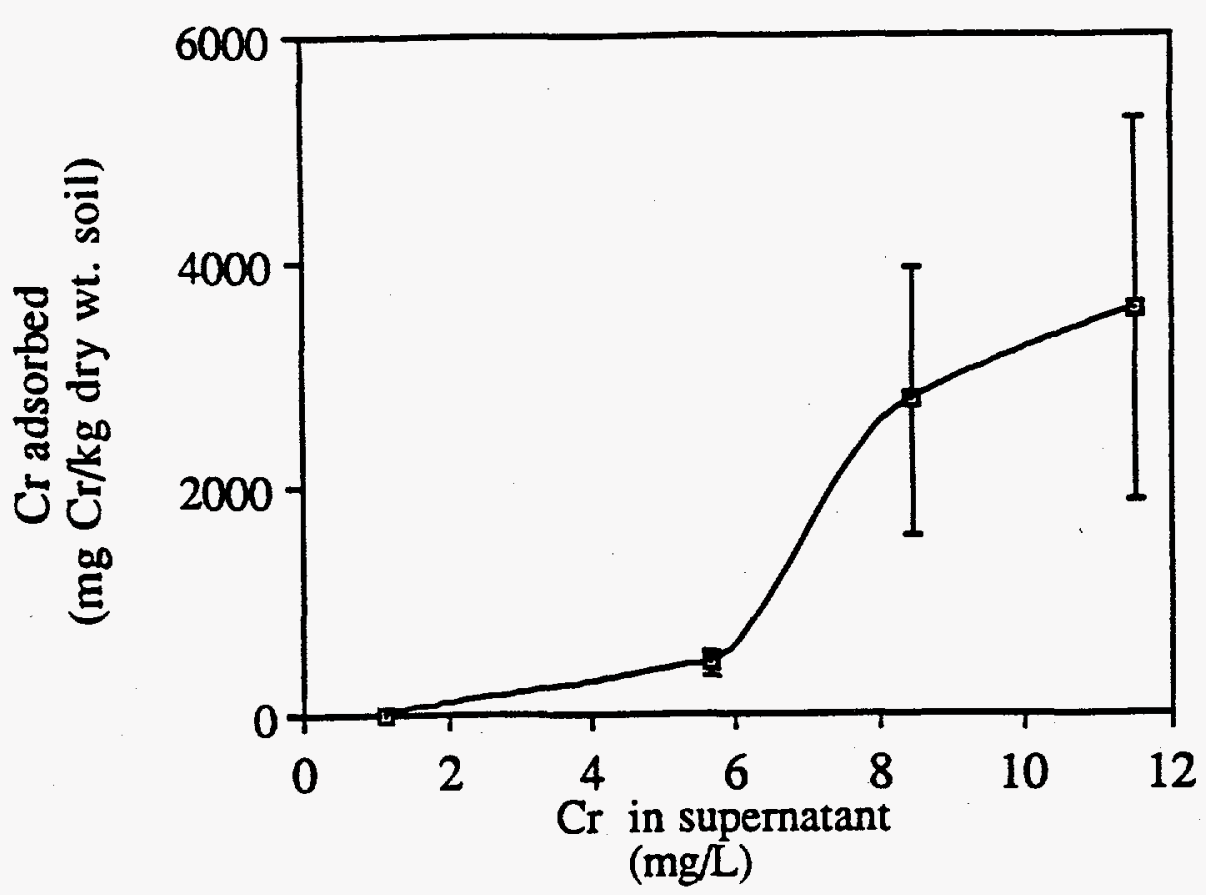

Figure 4. Chromium adsorption on wetland soil. 


\section{Task 2B: Development of Wetland Amendments}

Our literature search revealed that clay amendments are beginning to be used in Europe for $\mathrm{P}$ removal in agricultural drainage systems. We therefore, undertook studies on the use of inexpensive amendments to wetlands, such as modifiedclays and algae, to enhance the performance of a constructed wetland for the treatment of oil and gas well waste waters.

\section{Preparation of hec-CBDA-DT(HCDT)}

The scheme to prepare surfactant-modified clays is shown diagrammatically in Figure 5. The base clay is a smectite, specifically Na-hectorite (part I, Figure 5) This is treated initially with quaternary ammonium surfactant, cetyl benzyl dimethyl ammonium (CBDA) ion. Previous studies have shown that this cationic surfactant binds "irreversibly" to the interlayer and the external surfaces of the base clay (part II, Figure 5) (23-27). As a consequence, the CBDA-clay becomes hydrophobic and, if the adsorption density of CBDA is high, all of the cation exchange sites on the clay are " irreversibly " blocked. The next step is to contact CBDA-clay with a dialkyl amine Duomeen-T, (DT), a dissociable, water-insoluble surfactant, which has been shown to be a potential complexing agent for metal ions such as $\mathrm{Cu}$ (II) in solution around $\mathrm{pH} 8.0$ (28).

Duomeen- $\mathrm{T}$, is a commercially available, aliphatic diamine of the type (R-NH$\left.\left(\mathrm{CH}_{2}\right)_{3}-\mathrm{NH}_{2}\right)$ and the size of the alkyl group ranges from $\mathrm{C}_{12}$ to $\mathrm{C}_{18}$. The apparent molecular weight based on hydrocarbon assay is $330 \mathrm{~g} / \mathrm{mole}$ (17). Duomeen- $\mathrm{T}$, (DT), is insoluble in water and a solution of DT was prepared in isopropanol for use. As shown in part III of Figure 5, the " anchoring" of DT to CBDA-clay surface would occur via hydrophobic bonding. The net result would be to have the active end of DT to be pointing towards the solution side of the interface where it is most likely to encounter heavy metal ions.

In practice, the amount CBDA was fixed at $23 \%$ by weight of the CBDA-clay adduct. At this adsorption density of CBDA, the bulk of the interlayer and the external surface of the clay is coated with this surfactant and the surface charge was also minimal, as evidenced by a very low value of zeta potential (23). A fourfold ( on a molar basis) excess of DT was mixed with the flocs of hectorite-CBDA to form hectorite-CBDA-DT complex. This was washed extensively with deionized water to remove unreacted DT.

The possible mode of operation of this complex is pointed out in Figure 6. At low

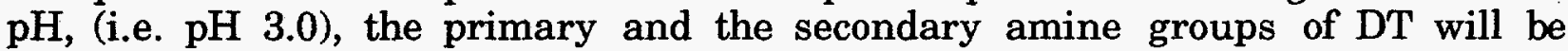
protonated. The resultant positive surface charge will repel cationic metal ions from the surface and minimize the adsorption of metal ions (upper panel, Figure 6). At $\mathrm{pH} 8.0$, both the amine groups will be significantly, if not fully, deprotonated. Under such conditions of low or zero surface charge metal ions can form a bidentate complex with both the primary and the secondary amine groups of DT (lower panels, Figure 6). 
I.
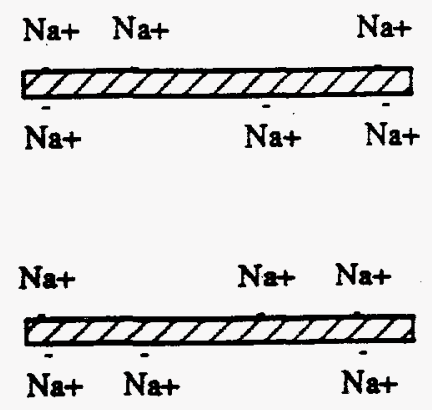

Base Clay (Hectorite)

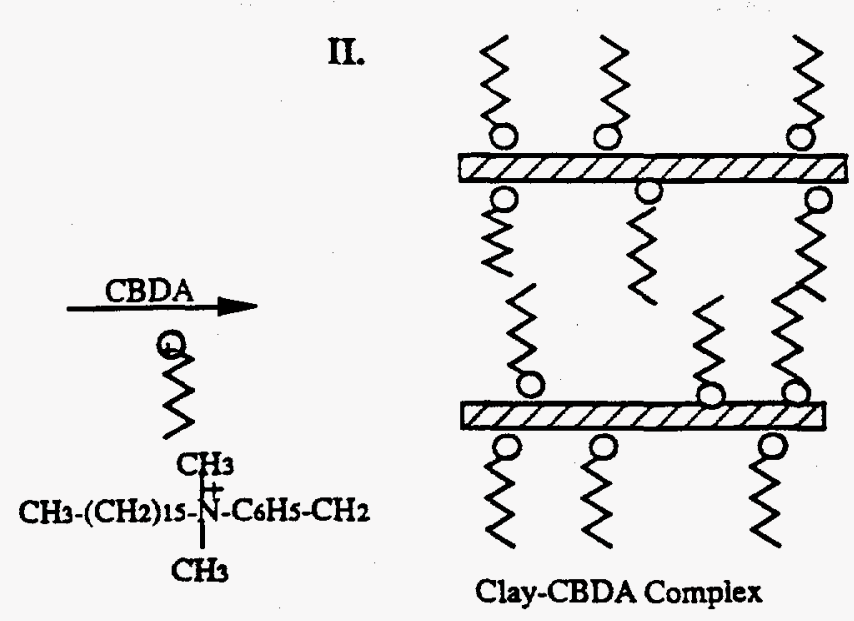

III.

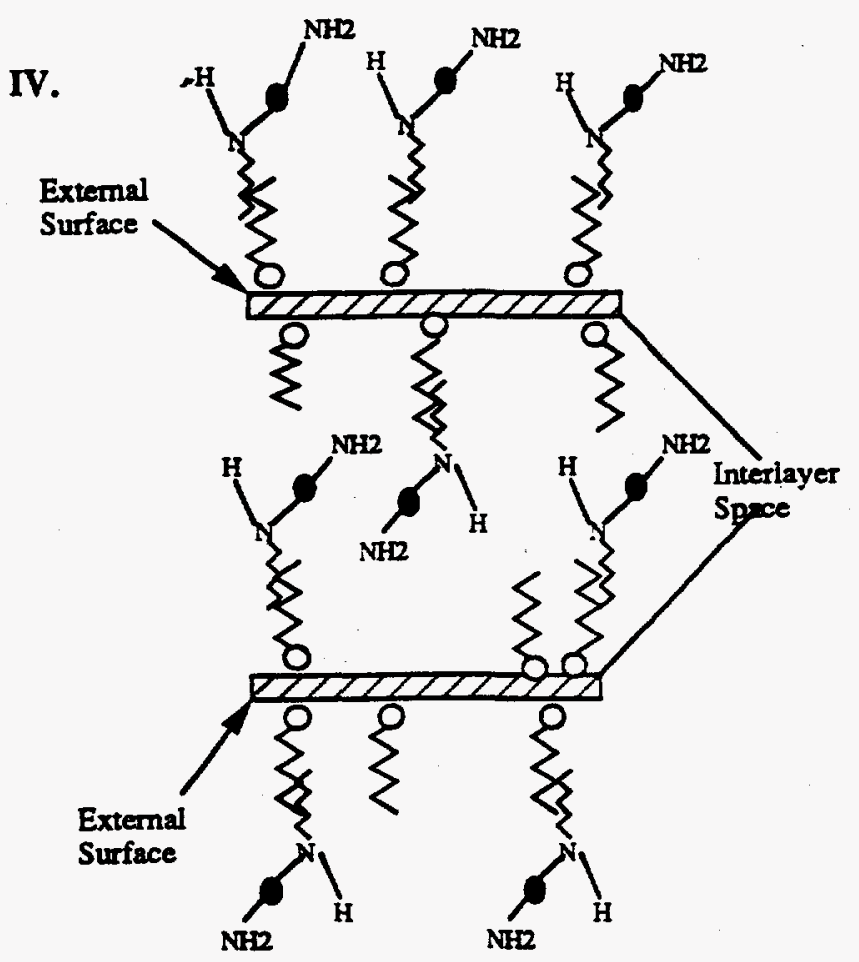

Clay-CBDA-DT Complex

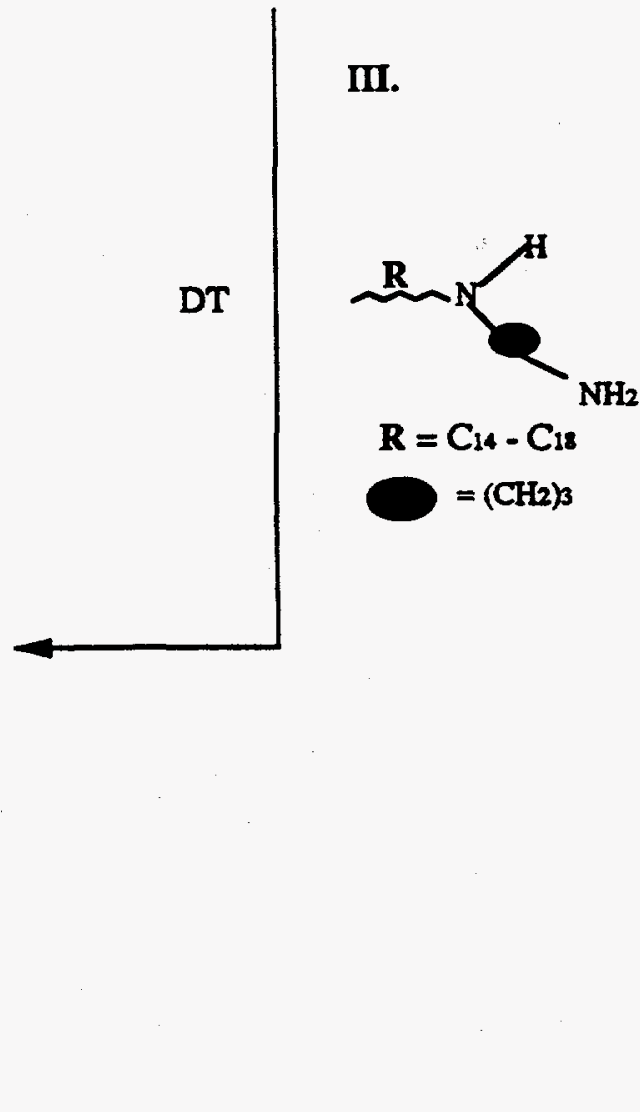

Figure 5. Preparation scheme of clay-CBDA-DT complex. 

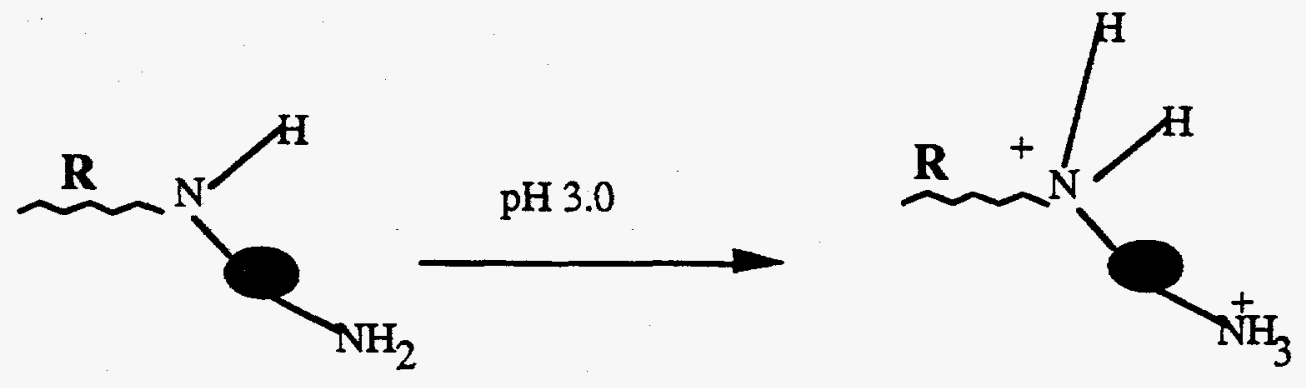

Both amines are protonated and very little metal ion binds
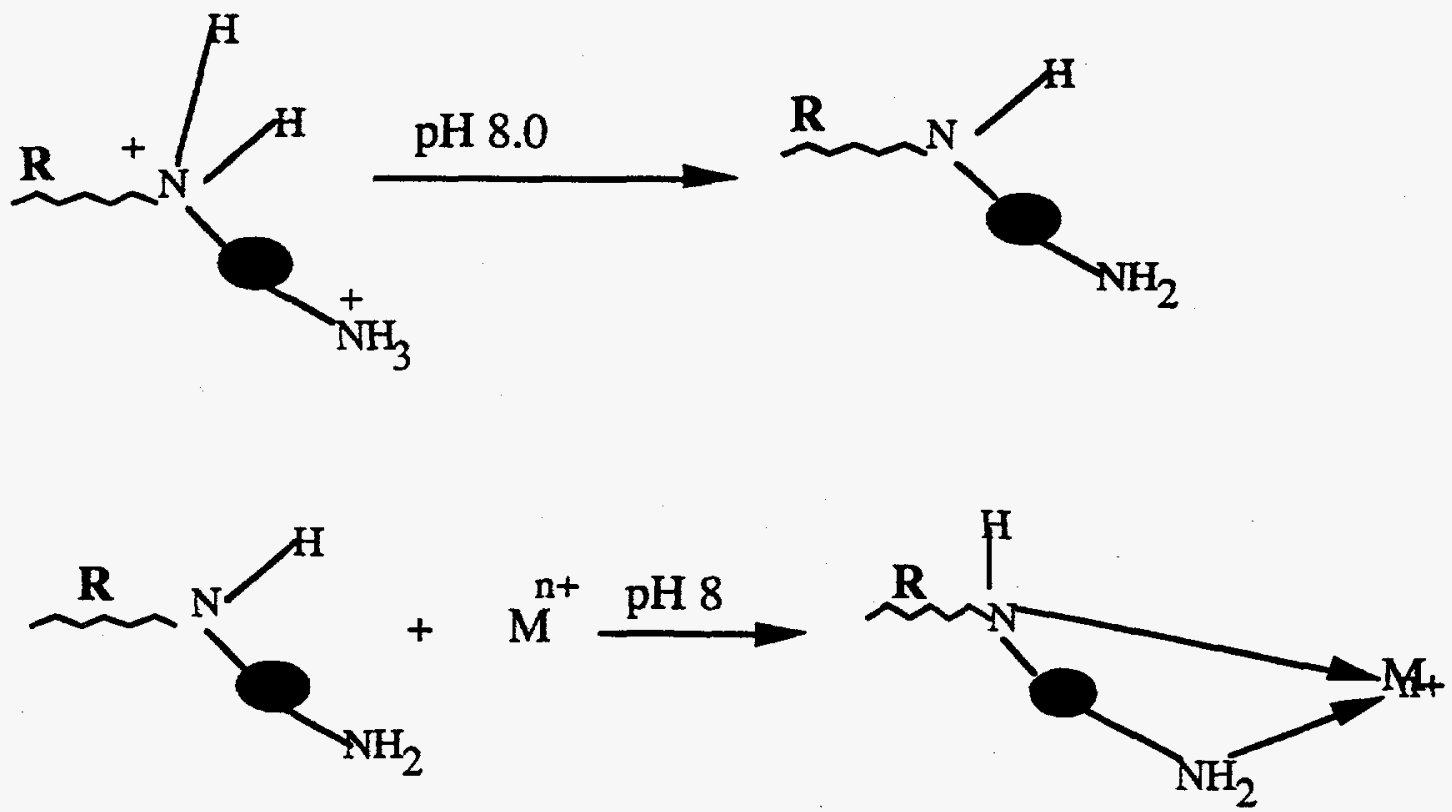

Figure 6. Proposed mechanism for the adsorption of cationic metal ions onto clay-surfactant complex. 


\section{Uptake of $\mathrm{Cu}$ (II) and Cd(II)}

The resultant hectorite-CBDA-DT complex adsorbed $\mathrm{Cu}$ (II) ions ( in low ppm levels) strongly at $\mathrm{pH} 7.2$ and desorbed the metal ions at $\mathrm{pH} 3.0$. In the case of $\mathrm{Cd}(\mathrm{II})$ ions, a strong adsorption maximum occurred at $\mathrm{pH} 8.0$ and the desorption of metal ions could be effected at $\mathrm{pH}$ 3.0. The active component in our adsorption scheme was an alkyl diamine, Duomeen-T. The same alkyl diamine can be and has been used to adsorb $\mathrm{Cr}(\mathrm{VI})$ and $\beta$-naphthoic acid from their respective aqueous solutions (see next section). In this case, the mode of adsorption would be counter ion binding or anion exchange.

\section{Preparation of MONT-DT}

Montmorillonite (SWy-1) was obtained from the Clay Minerals Society Repository and a size fraction $<2 \mathrm{~mm}$ in size was cleaned to remove carbonates by treatment with sodium acetate/acetic acid buffer at $\mathrm{pH} 3.8$. The treatment was continued by exchanging the counter ions on the clay with sodium ions using $1.0 \mathrm{M}$ solution of the latter. Following sodium exchange, the clay was washed with de-ionized water until the supernatant was free of $\mathrm{Cl}^{-}$ions ( as determined by the $\mathrm{AgNO}_{3}$ test). The resultant suspension was freeze-dried for later use.

A suspension of Montmorillonite ( $5 \mathrm{~g} ; 3.85 \mathrm{meq}$ of total charge, assuming a cation exchange capacity of $0.77 \mathrm{meq} / \mathrm{g}$ montmorillonite) was reacted with DT (5.355 g corresponding to $15.3 \mathrm{mmoles}$ or $30.6 \mathrm{meq}$ of charge when both the amine functions are fully protonated) at $\mathrm{pH}$ 6.0. The charge ratio between clay and DT was $1: 8$. The clay-DT suspension was continuously mixed and heated to $50^{\circ} \mathrm{C}$ for 2 hours. The reaction was continued at room temperature overnight with continuous mixing. The following exchange reaction was expected to occur:

$$
\text { MONT-Na }+ \text { DT }=\text { MONT-DT }+\mathrm{Na}
$$

The MONT-DT suspension was washed extensively with de-ionized water adjusted to $\mathrm{pH} 3.0$, following which, it was vacuum dried at $60^{\circ} \mathrm{C}$ for 10 hours and oven-dried at $105^{0} \mathrm{C}$ overnight.

Table 1. Properties of modified clays.

MONT-DT: $\underline{\mathrm{HCDT}}$

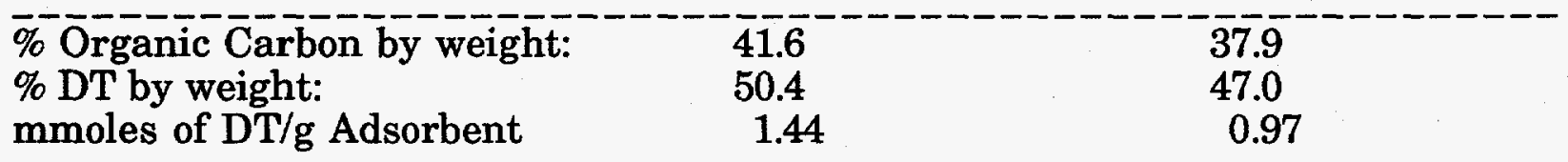


The above results (Table 1) indicate that almost all of DT reacted and formed a coating of DT over montmorillonite particles. Thus, a super equivalent adsorption of DT appears to have occurred and the surface of MONT-DT has become positively charged as a consequence, enabling MONT-DT to adsorb $\mathrm{Cr}$ (VI) and $\beta$ naphthoic acid by anion exchange.

\section{Adsorption of $\mathrm{Cr}(\mathrm{VI})$}

Experiments were conducted to study the uptake of $\mathrm{Cr}$ (VI) as a function of $\mathrm{pH}$. A $1000 \mathrm{ppm}$ stock solution of $\mathrm{Cr}$ (VI) was prepared and an aliquot was diluted to a final concentration of $20 \mathrm{ppm}$ in $\mathrm{Cr}(\mathrm{VI})$ in various buffer systems ranging from 3.0 to 9.0. A slurry of MONT-DT at $1 \mathrm{mg} / \mathrm{ml}$ was added to determine the extent of $\mathrm{Cr}$ (VI) adsorption after 24 hours of mixing. Controls (i.e. solutions containing identical $\mathrm{Cr}$ (VI) concentrations with no added adsorbent) were used to account for losses of $\mathrm{Cr}$ (VI) by processes other than adsorption to the modified-clay.

Results of $\mathrm{Cr}(\mathrm{VI})$ adsorption followed the $\mathrm{pH}$-dependent charging characteristics of MONT-DT . At low pH both the amine groups on DT are protonated and the positive charge facilitates $\mathrm{Cr}(\mathrm{VI})$ adsorption. As the $\mathrm{pH}$ increases the extent of positive charge on the surface decreases due to the deprotonation of the amine groups on DT, thereby reducing the amount of $\mathrm{Cr}(\mathrm{VI})$ adsorption. Adsorption isotherm for $\mathrm{Cr}(\mathrm{VI})$ uptake onto MONT-DT showed a limiting adsorption capacity of 2.4 mmoles $\mathrm{Cr}(\mathrm{VI}) / \mathrm{g}$ adsorbent.

\section{Adsorption of $\beta$-naphthoic acid}

Measurements on the uptake of $\beta$-naphthoic acid as a function of $\mathrm{pH}$ were also carried out. A stock solution of $50 \mathrm{ppm}$ was prepared, from which the initial NA concentration of $5 \mathrm{ppm}$ was obtained by dilution with buffer. The properties of $\beta$ naphthoic acid are listed below:

$$
\begin{array}{ll}
\text { Aqueous solubility: } & 70 \mathrm{ppm} \\
\text { pKa (29): } & 4.17
\end{array}
$$

The data from $\beta$-naphthoic acid (NA) adsorption as a function of $\mathrm{pH}$ were fitted to a Langmuir adsorption equation and the results are shown in Table 2.

The affinity of NA for modified-clays is significantly higher than it is for the wetland soil. This is related to the surface charge, positive for the modified-clays, and possibly negative for the wetland soil. Thus, anion exchange appears to be the dominant mechanism of adsorption of NA. The binding constant is much higher at $\mathrm{pH} 4.5$ than at 7.0, which means electrostatic contribution to the adsorption process is significant. However, the limiting capacity has a maximum at $\mathrm{pH} 7.0$ for both the adsorbents, and this indicates that the adsorption capacity is controlled by the degree of deprotonation of NA and the positive charge of the adsorbent. 
Table 2. Adsorption of NA by wetland soils and modified clays: Langmuir constants as a function of $\mathrm{pH}$.

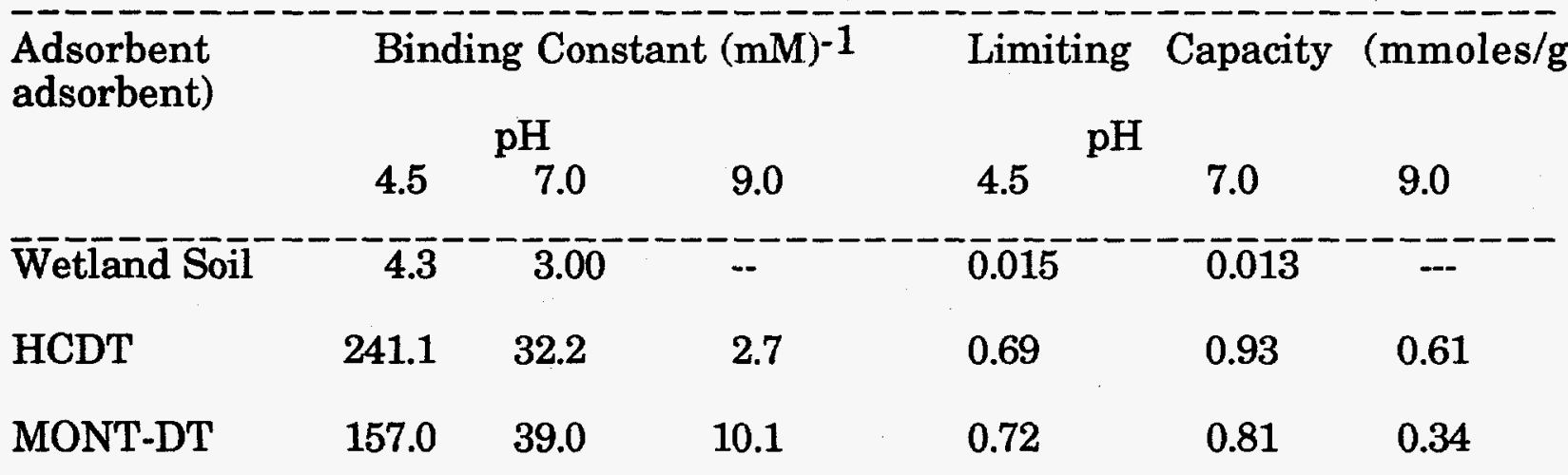

${ }^{*}$ The correlation coefficients for the fitted data ranged from 0.96 to 0.993

On the other hand, HCDT, which has a lower amount of DT on its surface appears to have a higher binding affinity and saturation capacity. Both HCDT and MONT-DT have nearly the same amount of surfactant on the surface. Thus, it would seem that hydrophobic partitioning of NA may be equally important.

\section{Task 2B: Development of Wetland Amendments: Algae}

Experiments were conducted to study cadmium uptake by the unicellular green alga Chlorella vulgaris.. These were 96 hour batch experiments with $50 \mathrm{ml}$ triplicate cultures in $125 \mathrm{ml}$ flasks. Algae were grown in media suggested for Chlorella vulgaris with a minor modification of using $\mathrm{FeCl}_{3}(2.5 \mathrm{mg} / \mathrm{L}$ ) rather than Fe-EDTA to minimize the chelating effect of EDTA on Cd uptake by the algae. The $\mathrm{pH}$ of the medium was 5.8. Exponentially growing cultures at an initial cell concentration of $2.5 \times 10^{8}$ cells/L were spiked with $\mathrm{Cd}$ in the form of $\mathrm{CdCl}_{2}$. The initial $\mathrm{Cd}$ concentration was $3 \mathrm{mg} / \mathrm{L}$. Biomass, final metal concentration, cell size distribution, and cell concentration were measured every 12 hours.

The extent of metal accumulation in 96 hours was greater than $0.1 \mathrm{~g} \mathrm{Cd} / \mathrm{g}$ dry wt. biomass. It was observed that $90 \%$ of the total accumulation occurred within the first 24 hours. An increase in the average cell size with little or no increase in cell concentration was noted in presence of Cd. Thus, it is concluded that Cd inhibited cell division, but it did not kill the algal cells.

The results are shown in Figure 7. 


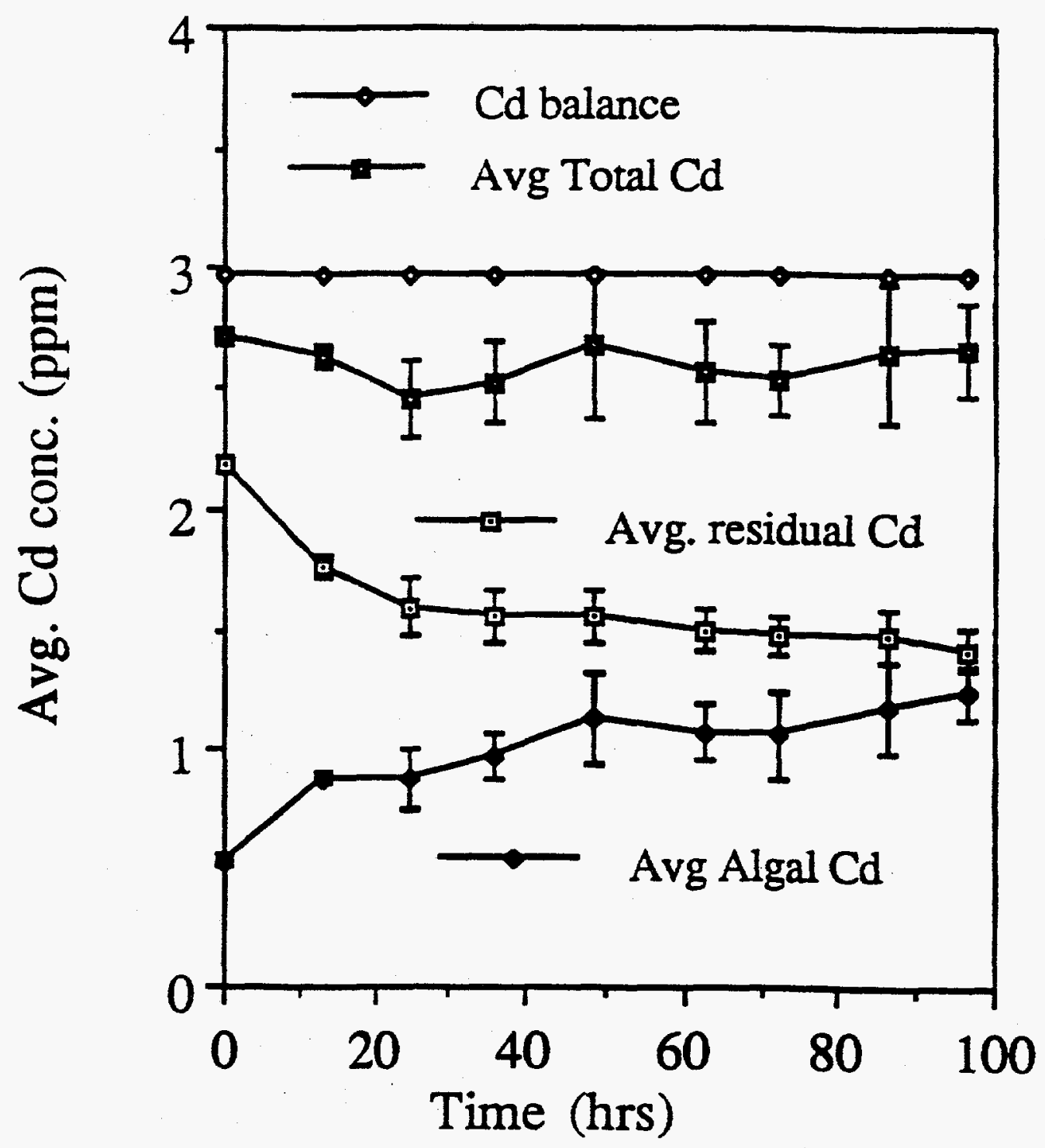

Figure 7. Adsorption of cadmium ions onto algal cells. 
An instantaneous uptake of Cd(II) ions amounting to around $30 \%$ of the final value is observed. This initial fraction is thought to arise from sites on the external surface of the cells. The metal accumulation continues for 96 hours, and the amount of metal ion adsorbed is greater than $0.1 \mathrm{~g} \mathrm{Cd} / \mathrm{g}$ dry wt. biomass. It is to be noted that $90 \%$ of the total accumulation occurs within the first 24 hours. The adsorption profile appears to be tri-phasic in time, comprising of an instantaneous, gradual, and a very slow process.

An increase in the average cell size with little or no increase in cell concentration is noted in presence of Cd. Thus, it is concluded that Cd inhibited cell division, but it did not kill the algal cells.

\section{Task 3: Dynamics of the Uptake and Fate of Toxic Organics by Laboratory Wetlands (LWs)}

A laboratory-type wetland (microcosm) was designed and built as described under Task 2A. The details are as follows. Cattails (Typha latifolia) were grown in 50 liter lysimeters. A total of 90 lysimeters were constructed. Each lysimeter was filled with approximately 8 " to 12 " of wetland soil (obtained from an operating wetland in Michigan) and four cattails were planted per lysimeter. These LWs were moved to a green house located inside Matthei Botanical Gardens operated by the University of Michigan. The LWs were monitored periodically to check on their well-being.

Uptake of organics or heavy metals by LWs were done in the following manner:

(1) Removed the overlying water and replaced with fresh tap water. In some cases, $2-3$ gallons of peat in the form of a thick paste were layered on the soil matrix prior adding the tap water. The depth of water was set to either 3 or 7 inches from the surface of the soil-peat layer.

(2) After $24 \mathrm{hr}$ equilibration, the height of the water column was determined with a yard stick and the overlying water was spiked with phenol or $\beta$ naphthoic acid or heavy metals to a pre-determined concentration. Following the addition of the toxic organics or heavy metals the water was mixed manually with a paddle for about $1-2$ minutes and was left undisturbed thereafter.

(3) Water samples were collected prior to the start of the experiment and periodically during the experiment. The temperature and the $\mathrm{pH}$ were noted.

The concentration of phenol in the supernatant water was determined spectrophotometrically (UV absorbance @ $268 \mathrm{~nm}$ ) following steam distillation of the water sample or by the well-known 4 -aminoantipyrene method without steam distillation (30). On the other hand, $\beta$-naphthoic acid was assayed fluorimetrically after filtering the sample and the standards through a $0.22 \mathrm{~m} \mathrm{~m}$ filter using the standard addition method. Details of the assay are given in Table 3. 
Table 3. Assay of phenol and $\beta$-naphthoic acid.

\section{Phenol Assay Conditions:}

Initial Concentration:

Sample Size:

Analysis Method:
50 , or $100 \mathrm{ppm}$

$50 \mathrm{ml}$

Steam Distillation and UV Absorbance of the distillate @ $268 \mathrm{~nm}$ or the 4-aminoantipyrene method without steam distillation.

Room Temp.

$7.5-8.5$

$\mathrm{pH}$

$\beta$-Naphthoic Acid Assay Conditions:

Initial Concentration:

$10 \mathrm{ppm}$

Sample Size:

$20 \mathrm{ml}$

Analysis:

Filter through $0.2 \mathrm{~mm}$ membrane,Fluorescence detection using the Standard Addition method with two standard spikes of 1.0 and $2.5 \mathrm{ppm}$.

Ex. $\quad 287 \mathrm{~nm}$

Em. $360 \mathrm{~nm}$

Temp. and pH:

Room Temp. and 7.5, respectively.

A preliminary sorption experiment was conducted on a single wetland, and based on the data obtained, phenol and $\beta$-naphthoic acid uptake was carried out respectively on a separate set of 3 wetlands each. Experiments to determine the potential evaporative losses of phenol were also undertaken. The combined results of the studies on phenol uptake by the wetlands are shown in Figures 8-10. In Figure 11, the results of $\beta$-naphthoic acid adsorption are displayed.

\section{Phenol Uptake}

Figure 8 is a calibration curve for the assay of phenol using the UV absorbance method. Concentrations as low as $5 \mathrm{ppm}$ could be determined with very little uncertainty. Even though the water samples had a slight coloration, UV absorbance method following steam distillation was found to be quite effective and reproducible. The validity of this approach is verified in Figure 9. Phenol standards were spiked into water drawn from one of the wetlands (not used in the uptake measurements) and the phenol assay was performed following steam distillation of the water samples. The amount of phenol recovered was compared with the amount initially added. The recovery was close to $100 \%$. Secondly, the calibration line was identical to the one obtained with phenol standards (compare 
the linear calibration equations shown in Figures 8 and 9). A second method of phenol assay was the 4-aminoantipyrene method, which could be applied directly to the supernatant water drawn from the wetland. Spike experiments similar to the ones described above revealed that the 4-aminoantipyrene method was reproducible and accurate. The latter was used exclusively for the bulk of the phenol assays carried out in this study.

Phenol uptake by laboratory-type wetlands is quite rapid, and appears to be linear with respect to time. The results shown in Figure 10 indicate that a linear fit of the data has a high value of correlation coefficient. The disappearance of phenol, however, is most likely mediated by a number of processes such as biodegradation, simple sorption, and evaporation. Each data point shown in Figure 10 is an average of two measurements at each time period and the two lines represent fits to the data obtained from three different wetlands. All the wetlands show similar behavior.

The potential loss of phenol through evaporation was examined using surface evaporation method. Even though there was some evaporative loss of phenol, the extent of removal of phenol by LWs appears to be dominated by sorption and biodegradation.

\section{Effect of System Variables}

The effect of phenol uptake was also monitored as a function of the following system variables and the results are summarized in Table 4.

(1) Initial phenol concentration ( 20 and $100 \mathrm{ppm}$ )

(2) Ambient water temperature $\left(28\right.$ and $15^{\circ} \mathrm{C}$; corresponding to the average summer and fall temperatures )

(3) Water Depth ( 3 and 7 ")

(4) Addition of peat

Table 4. Effect of system variables on phenol uptake by LWs.

System Variable

Initial Phenol Conc.

Water Temperature

Water Depth

Addition of peat

\section{Öbserved Effect}

Rate of uptake dependent on initial phenol conc.

Higher evaporative losses in summer

No significant effect

Moderate enhancement. Peat is known to promote uptake of toxic organics. The observed effect (moderate enhancement ) may be related to its low organic carbon content in relation to the total amount of organic carbon present in LWs. 


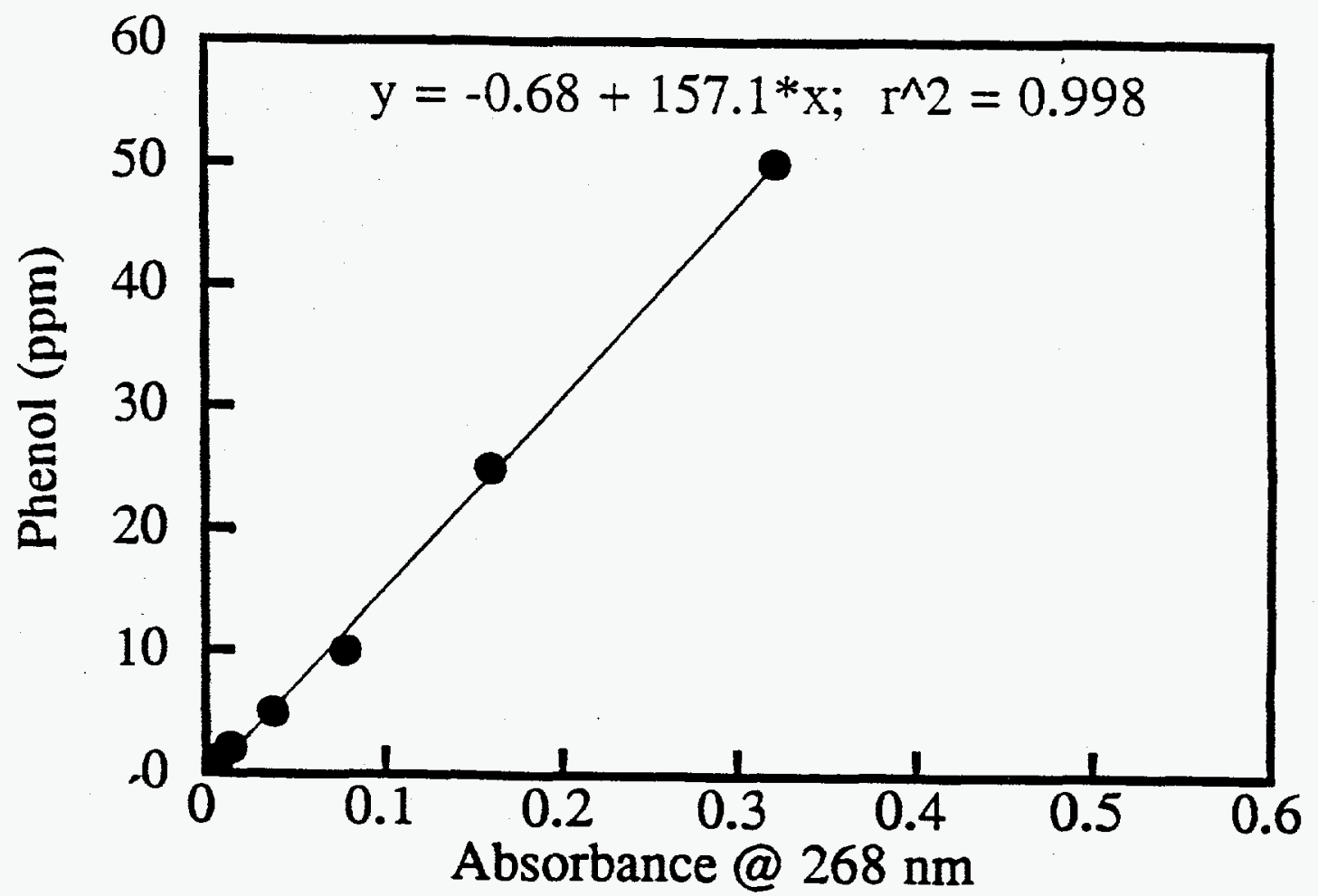

Figure 8. Phenol calibration curve.

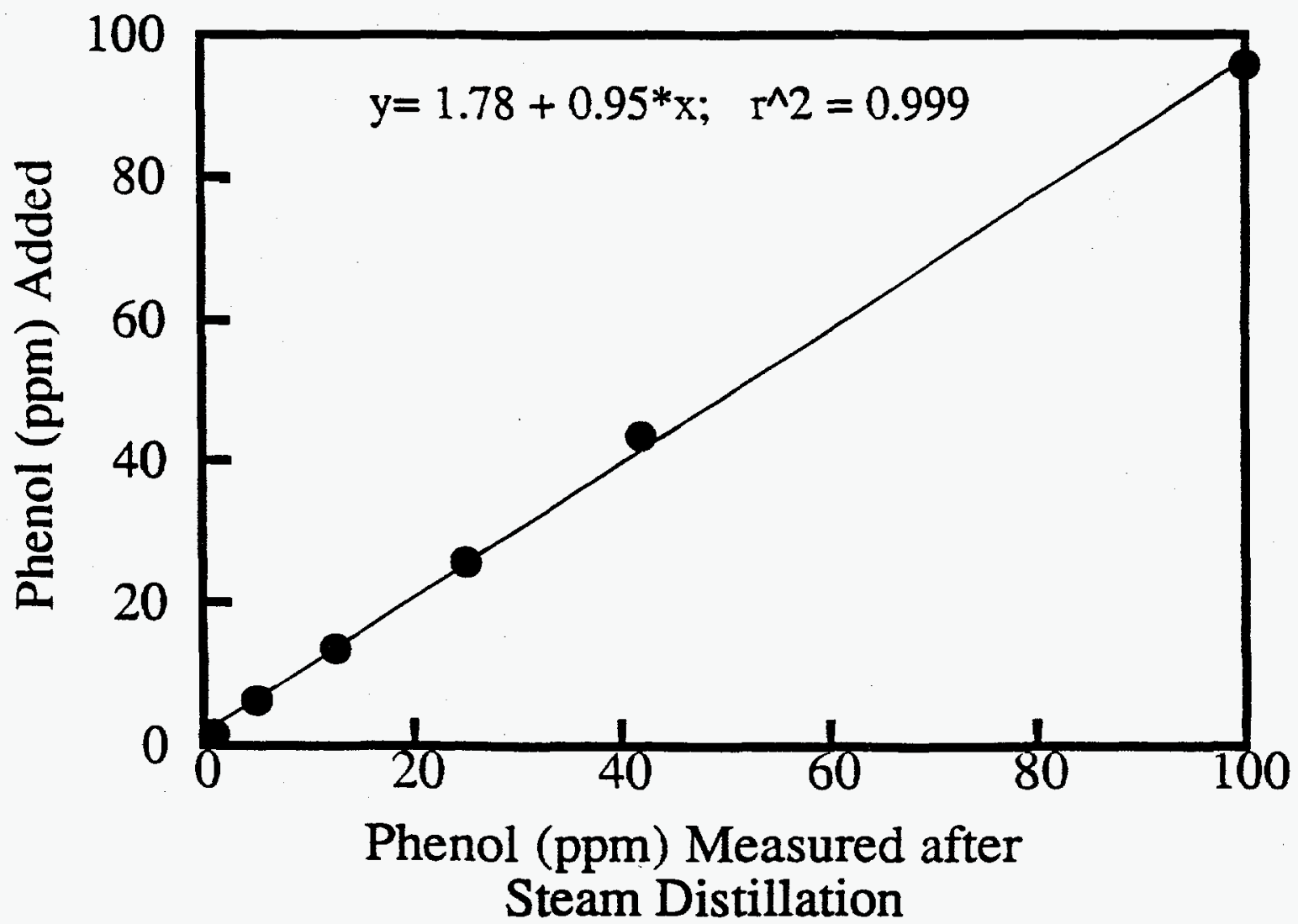

Figure 9. Comparison of phenol assay before and after steam distillation. 


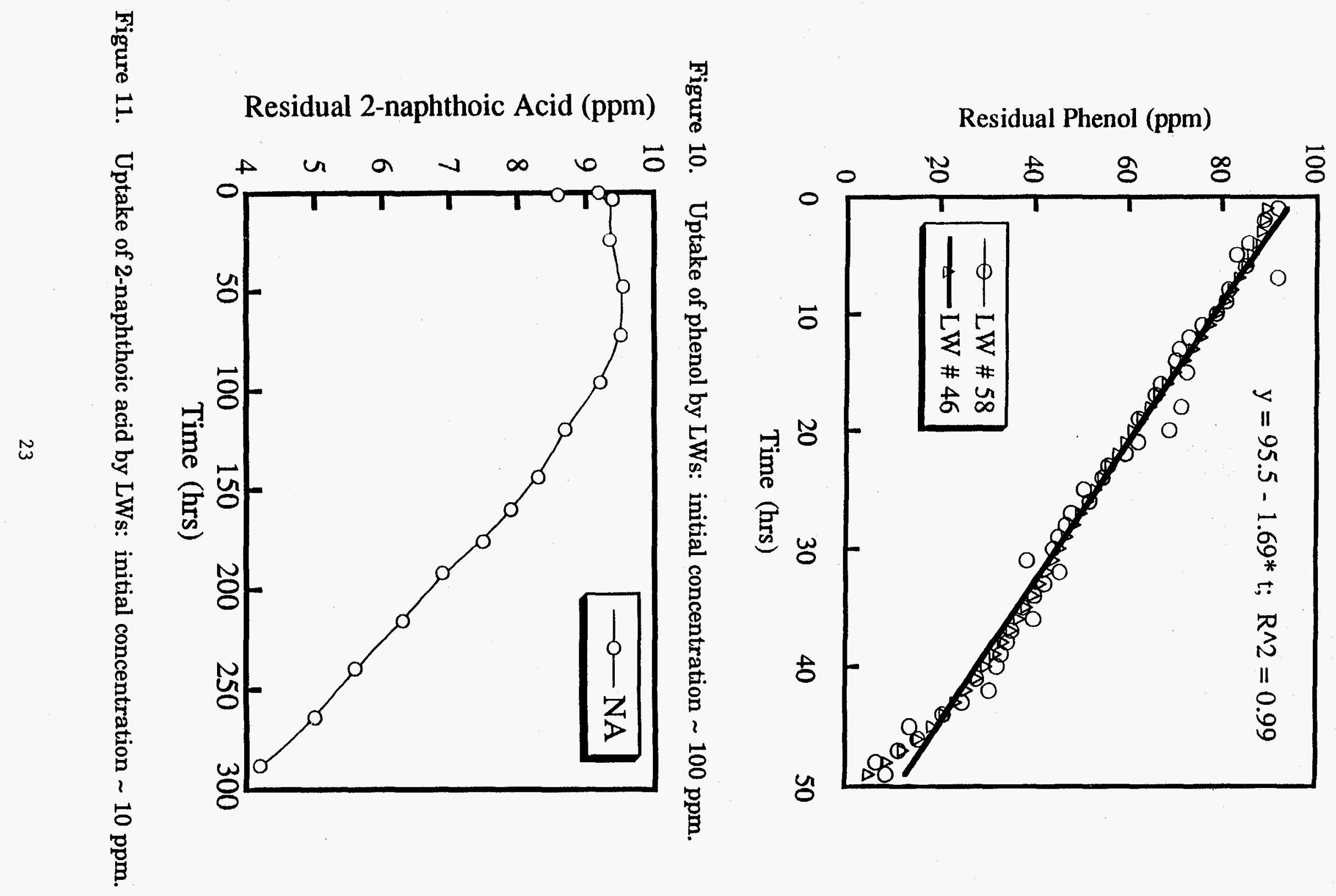




\section{B-naphthoic acid sorption}

The disappearance of $\beta$-naphthoic acid from the supernatant water was much slower than phenol uptake. The results are shown in Figure 11. Even after 12 days, the loss of NA from the supernatant was only around 50\%. The temperature and $\mathrm{pH}$ were nearly the same as in the phenol uptake experiments. The combined use of filtration and the standard addition method enabled us to quantify NA concentrations with a high level of reproducibility. The fact that the disappearance of NA is a much slower process would indicate that a loss mechanism such as evaporation may be unimportant. Sorption to various components of the wetland appears to be a main removal mechanism. It is however possible that adsorption of NA to different components of the wetland is not of the high affinity type. Biodegradation can not be ruled out because naphthalene and substituted naphthalenes are known to be biodegraded rapidly and easily.

\section{Modeling of the fate of phenol in laboratory wetlands (LWs)}

A mass balance model has been developed to quantify the fate of phenol in LWs. The model is based on the postulate that the fate of phenol in LWs can be attributed to a combination of (1) evaporation of solute and solvent, (2) adsorption of phenol onto various components of $\mathrm{LW}$ and (3) its biodegradation, both in solution and at solid-liquid interface. As an initial approximation, the latter two processes have been lumped together and incorporated into the model as an unit operation. Both zero order and first order kinetics for the disappearance of phenol have been considered. Evaporative losses of water and phenol have also been taken into account. Phenol and water mass balance equations were simultaneously solved as described below. The water balance accounts for evaporation, while the phenol balance accounts for phenol evaporation, adsorption and degradation.

The mass balance equations (equations $1-3$ and $6-8$ ) are given below.

Fate of phenol in a laboratory wetland: zero order kinetics

$$
\begin{gathered}
\frac{d\left(V_{p}\right)}{d t}=-k_{A 0} S_{A}-E_{p} C_{p} A \\
C_{p} A\left(E_{p}-E\right)+V \frac{d\left(C_{p}\right)}{d t}=-k_{A 0} S_{A} \\
V=V_{o}-E A t \\
C_{p}=\left\{\left[k_{A 0} S_{A}+A C_{p 0}\left(E_{p}-E\right)\right]\left(\frac{V_{0}-E A t}{V_{0}}\right)\left(\frac{E_{p}-E}{E}\right)_{-k_{A 0} S_{A}}\right]\left[\frac{1}{A\left(E_{p}-E\right)}\right]
\end{gathered}
$$


If $\mathrm{E}_{\mathrm{P}}=0$ :

$$
\mathrm{C}_{\mathrm{p}}=\frac{\mathrm{C}_{\mathrm{po}} \mathrm{V}_{0}-\mathrm{k}_{\mathrm{A} 0} \mathrm{~S}_{\mathrm{A}} \mathrm{t}}{\mathrm{V}_{0}-\mathrm{EAt}}
$$

A surface area of water in $\mathrm{LW}, \mathrm{m}^{2}$

$\mathrm{C}_{\mathrm{p}}$ phenol concentration, $\mathrm{gm} / \mathrm{m}^{3}$

$\mathrm{E}^{\mathrm{p}} \quad$ evaporation rate for water, $\mathrm{m} / \mathrm{yr}$

$E_{p} \quad$ evaporation rate for phenol, $\mathrm{m} / \mathrm{yr}$ )

$\mathbf{k}_{\mathrm{A} 0}$ rate constant for phenol removal, $\mathrm{gm} / \mathrm{m}^{2} / \mathrm{yr}$

$\mathrm{S}_{\mathrm{A}} \quad$ surface area of reactive components of $\mathrm{LW}, \mathrm{m}^{2}$

$\mathrm{t}$ time, $\mathrm{yr}$

$\mathrm{V}$ volume, $\mathrm{m}^{3}$

subscript $0=$ initial value

Fate of phenol in a laboratory wetland: first order kinetics

$$
\begin{gathered}
\frac{d\left(V C_{p}\right)}{d t}=-k_{A 1} S_{A} C_{p}-E_{p} C_{p} A \\
C_{p} A\left(E_{p}-E\right)+V \frac{d\left(C_{p}\right)}{d t}=-k_{A 1} S_{A} C_{p} \\
C_{p}=C_{p o} \cdot\left\{\frac{V_{0}-E A t}{V_{0}}\right\} \frac{\left.\frac{k_{A 1} S_{A}+A\left(E_{p}-E\right)}{E A}\right)}{E}
\end{gathered}
$$

$\mathrm{k}_{\mathrm{A} 1} \quad$ rate constant for phenol removal, $\mathrm{m} / \mathrm{yr}$

An analytical solution for phenol concentration as a function of time was obtained assuming zero or first order dependence of phenol degradation. Equations 1 - 3 represent mass balance equations for the overall process driven by zero order kinetics. Similar equations for the first order degradation kinetics are numbered 6 - 7. The solutions are given in equations $4-5$ and 8 , respectively for zero and first order processes.

Using the solver function on an Excel ${ }^{\mathrm{TM}}$ spreadsheet, the experimentally observed phenol concentration vs. time data were used to solve for the specific rate constant with the geometric surface area of the wetland, initial phenol concentration, and initial water volume as input parameters. The difference between the calculated and the observed values of phenol concentrations for each data set was calculated and this difference was minimized to obtain an optimal solution.

In some cases, a simplification of mass balance equations was attempted by neglecting phenol evaporation rate in relation to water evaporation rate due to the low vapor pressure of phenol at ambient temperatures. These were solved in an 
identical manner except that the value of $E_{p}$ was set to zero. Both zero order and first order kinetics were used to model the stoichiometry of phenol disappearance. A typical set of results is shown in Figures 12 and 13 respectively for zero and first order degradation kinetics. The values of input and calculated parameters are listed in Table 5.

Table 5: Calculated and Input model parameters for phenol disappearance in LWs:

$\begin{array}{lll} & & \\ \text { Model Parameter } & & \\ & & \\ \mathrm{k}_{\mathrm{A}} \mathrm{S}_{\mathrm{A}} & 15.7-17.6(\mathrm{gm} / \mathrm{yr}) & 1.15-1.44\left(\mathrm{~m}^{3} / \mathrm{yr}\right) \\ \mathrm{E}_{\mathrm{p}} & 8.9-20.5 \mathrm{E}-05(\mathrm{~m} / \mathrm{yr}) & 8.06 \mathrm{E}-05(\mathrm{in} / \mathrm{hr}) \\ \mathrm{E} & 1.01(\mathrm{~m} / \mathrm{yr}) & 1.01(\mathrm{~m} / \mathrm{yr}) \\ \mathrm{A} & 0.134\left(\mathrm{~m}^{2}\right) & 0.134\left(\mathrm{~m}^{2}\right)\end{array}$

The values listed in Table 5 represent the results of model calculations that produced minimum error between the observed and fitted data. For example, the frequency distribution of the values of $\mathrm{K}_{\mathrm{A}} \mathrm{S}_{\mathrm{A}}$ obtained from a large number of $\mathrm{LWs}$ has been used has been used to calculate the spread in the reported values.

From the data shown in Figures 12 and 13 it is clear that zero-order degradation applies to lower initial phenol concentrations $\left(17-25 \mathrm{gm} / \mathrm{m}^{3}=\mathrm{ppm}\right)$, and first-order degradation process can well account for the disappearance of phenol at higher initial phenol concentrations $\left(90-112 \mathrm{gm} / \mathrm{m}^{3}=\mathrm{ppm}\right)$. 


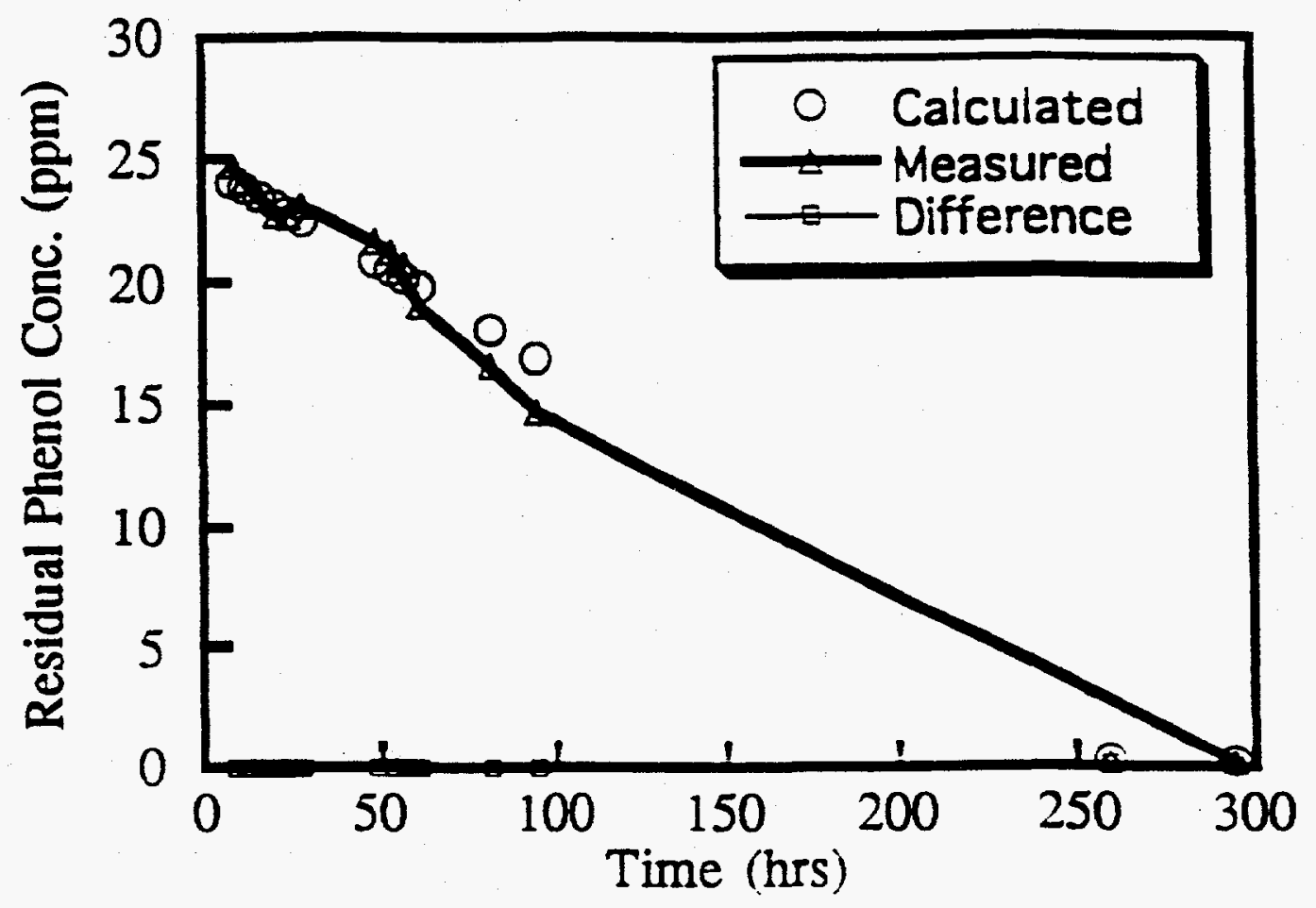

Figure 12. Modeling the fate of phenol in LWs: zero order disappearance kinetics: low initial phenol concentration.

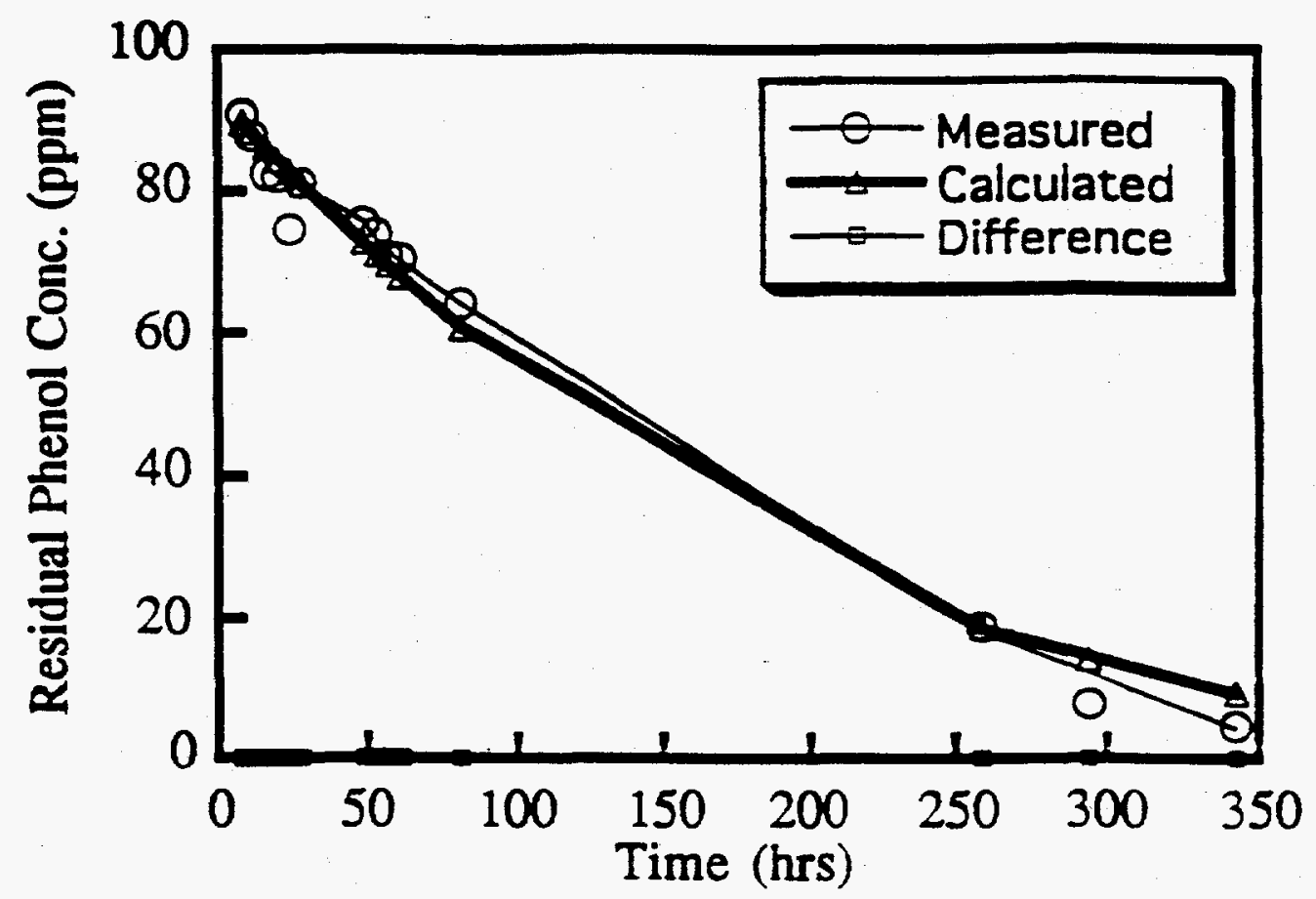

Figure 13. Modeling the fate of phenol in LWs: first order disappearnace kinetics: high initial phenol concentration. 
Task 3A: Dynamics of the Uptake of Heavy Metals Singly and in Nonstoichiometric Combination by Laboratory Wetlands (LWs).

Heavy metal uptake experiments were conducted in the following manner:

Removed the overlying water and replaced with fresh tap water. In some cases, $2-3$ gallons of peat in the form of a thick paste were layered before adding tap water. These LWs are designated with a ' $\mathrm{P}$ ' after their number. Water depth was set to be either 3 or 7 inches from the surface of the soil matrix.

After $24-\mathrm{hr}$ equilibration, the height of the water column was measured again and the overlying water was spiked with heavy metal solutions singly or in a non-stoichiometric combination to a pre-determined nominal concentration. Following the addition of the heavy metal, the water was mixed manually with a paddle and was left undisturbed thereafter. In the case of $\mathrm{Cu}$ (II) uptake experiments, $\mathrm{Li}$ ions were mixed in with $\mathrm{Cu}(\mathrm{II})$ ions. Since $\mathrm{Li}^{+}$is known to be a conservative tracer, its concentration in the supernatant water can be used as a guide to determine the approach to steady state conditions.

Collected water samples prior to the start of the experiment and periodically during the experiment. The temperature, water depth and the $\mathrm{pH}$ were noted.

Aqueous phase concentrations of $\mathrm{Cu}(\mathrm{II}), \mathrm{Cr}(\mathrm{VI})$ and $\mathrm{Li}^{+}$were measured using Perkin-Elmer AA spectrometer after allowing the supernatant to settle for $24-48$ hrs.

\section{Cu(II) uptake}

It can be seen ( Figure 14) that $\mathrm{Cu}(\mathrm{II})$ uptake shows a tri-phasic behavior. There is an initial phase during which a portion of $\mathrm{Cu}(\mathrm{II})$ is rapidly removed followed by a second phase lasting up to 50 hours when $\mathrm{Cu}$ (II) removal is gradual. These two phases may correspond to partial hydrolysis and precipitation of $\mathrm{Cu}$ ions and a slow adsorption of $\mathrm{Cu}(\mathrm{II})$ onto various components of LWs, respectively. Since LWs, with or without peat, show similar behavior, it appears that peat has minimal effect on $\mathrm{Cu}$ (II) adsorption. Beyond 50 hours, the rate of removal is quite slow and there is an apparent tendency for the $\mathrm{Cu}$ (II) concentration to level off. This is attributed to a slow dispersion of $\mathrm{Cu}$ (II) into the underlying pore water of the LWs.

One of the LWs (LW \# 36; no peat added) showed a much larger and faster uptake of $\mathrm{Cu}$ (II) compared to any of the other LWs. Results obtained for $\mathrm{Li}^{+}$uptake by the same LW were used to clarify the anomalous results observed with LW \# 36. It was found that $\mathrm{Li}^{+}$data also showed a similar atypical time profile. Since $\mathrm{Li}^{+}$is a 
conservative tracer, it was concluded that a contamination of this $\mathrm{LW}$ may have occurred. Therefore, the data from LW \# 36 were not used in subsequent analysis. Thus, the use of $\mathrm{Li}^{+}$tracer is shown to be helpful in sorting out real effects from artifacts when dealing with complicated systems such as LWs.

Figure 14 also reveals that, for the LWs considered here, it takes about 150 hours for the system to attain steady state. Secondly, it became clear that $\mathrm{Li}^{+}$data could be used to normalize $\mathrm{Cu}$ (II) uptake measurements so that the effects of dilution and dispersion of $\mathrm{Cu}$ (II) ions through diffusive mass transfer into underlying pore water of the LW could be taken into account. Data from the triplicate set of measurements (shown in Figure 14) were averaged and normalized by the apparent $\mathrm{Li}^{+}$" disappearance " data and the normalized average results revealed that:

(1) Between $75-85 \%$ of $\mathrm{Cu}$ (II) ions (at an initial concentration of $10 \mathrm{ppm}$ ) can be removed by LWs constructed as a part of this study.

(2) $\mathrm{Li}^{+}$data can be used to normalize heavy metal ion uptake data in complicated systems such as LWs.

(3) Addition of peat has surprisingly minimal effect on $\mathrm{Cu}$ (II) uptake by LWs.

\section{Cr(VI) Uptake}

Cr(VI) uptake experiments were also studied in triplicate, i.e. three LWs per experiment. The effect of peat addition was also monitored in triplicate. Water depth was maintained at 7 inches and the initial concentrations of $\mathrm{Cr}$ (VI) was nominally $16 \mathrm{ppm}$. $\mathrm{pH}$ was between $5.5-6.5$ and did not change during the course of the experiment. The results are shown in Figure 15.

The uptake of $\mathrm{Cr}$ (VI) appears to be an exponential function of time. During the first 100 hours the extent of $\mathrm{Cr}(\mathrm{VI})$ removal ranges from $60-85 \%$. It should be noted that the data shown in Figure 15 have been normalized with respect to initial $\mathrm{Cr}$ (VI) concentration in each LW. Thus, the observed variations in $\mathrm{Cr}$ (VI) uptake may be related to the $\mathrm{pH}$ in different LWs. It may be noted that $\mathrm{pH}$ varied from 5.5 - 6.5 and $\mathrm{Cr}$ (VI) adsorption may be quite sensitive to $\mathrm{pH}$ in this range. Secondly, the predominant chemical species of $\mathrm{Cr}$ (VI) in solution changes from $\mathrm{HCrO}_{4}^{-}$to $\mathrm{CrO}_{4}{ }^{2-}$ (31). The addition of peat had no measurable effect on $\mathrm{Cr}(\mathrm{VI})$ removal from aqueous solutions by LWs. In this respect, $\mathrm{Cr}$ (VI) uptake results correspond closely to similar findings on $\mathrm{Cu}$ (II) uptake as mentioned above. 


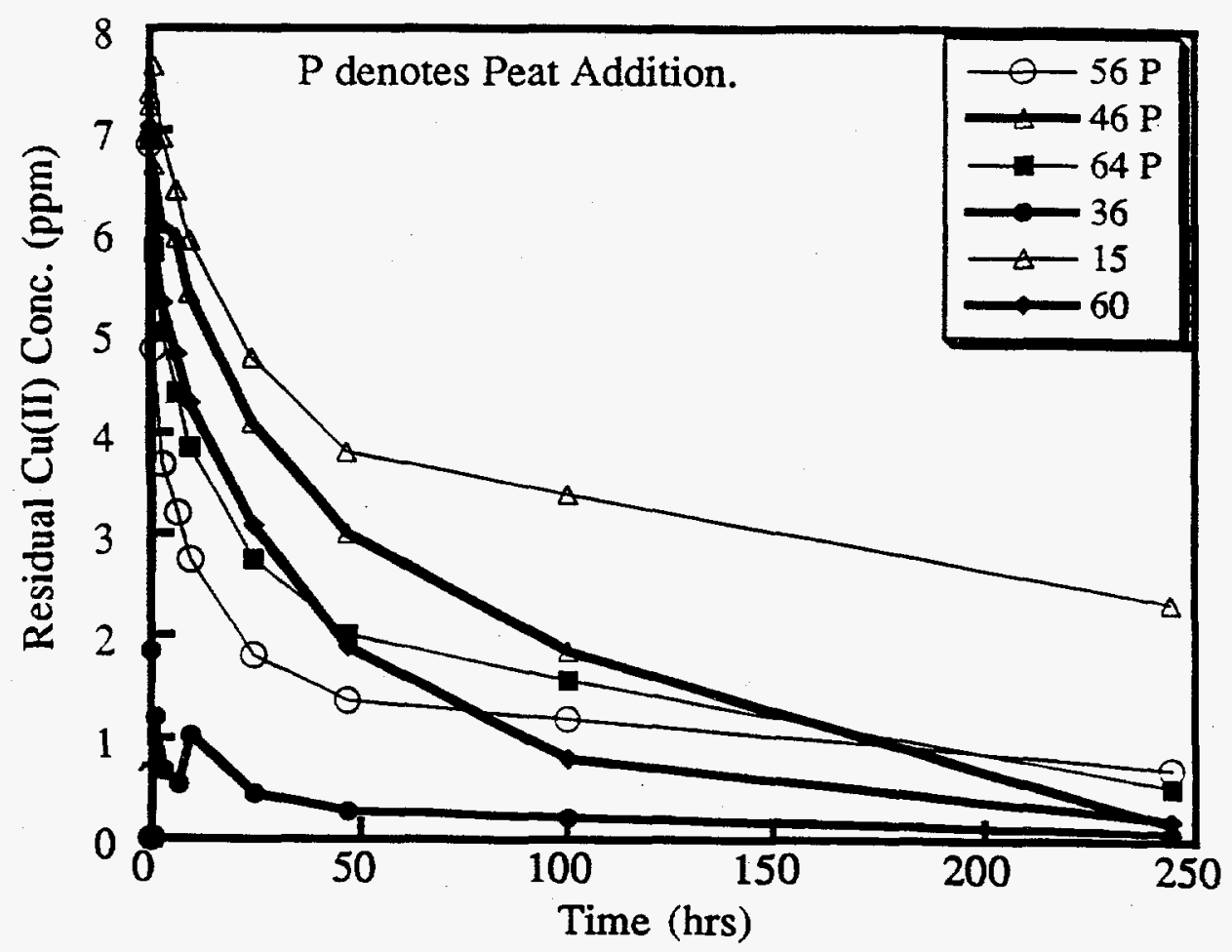

Figure 14. Dynamics of copper (II) uptake by LWs: effect of added peat.

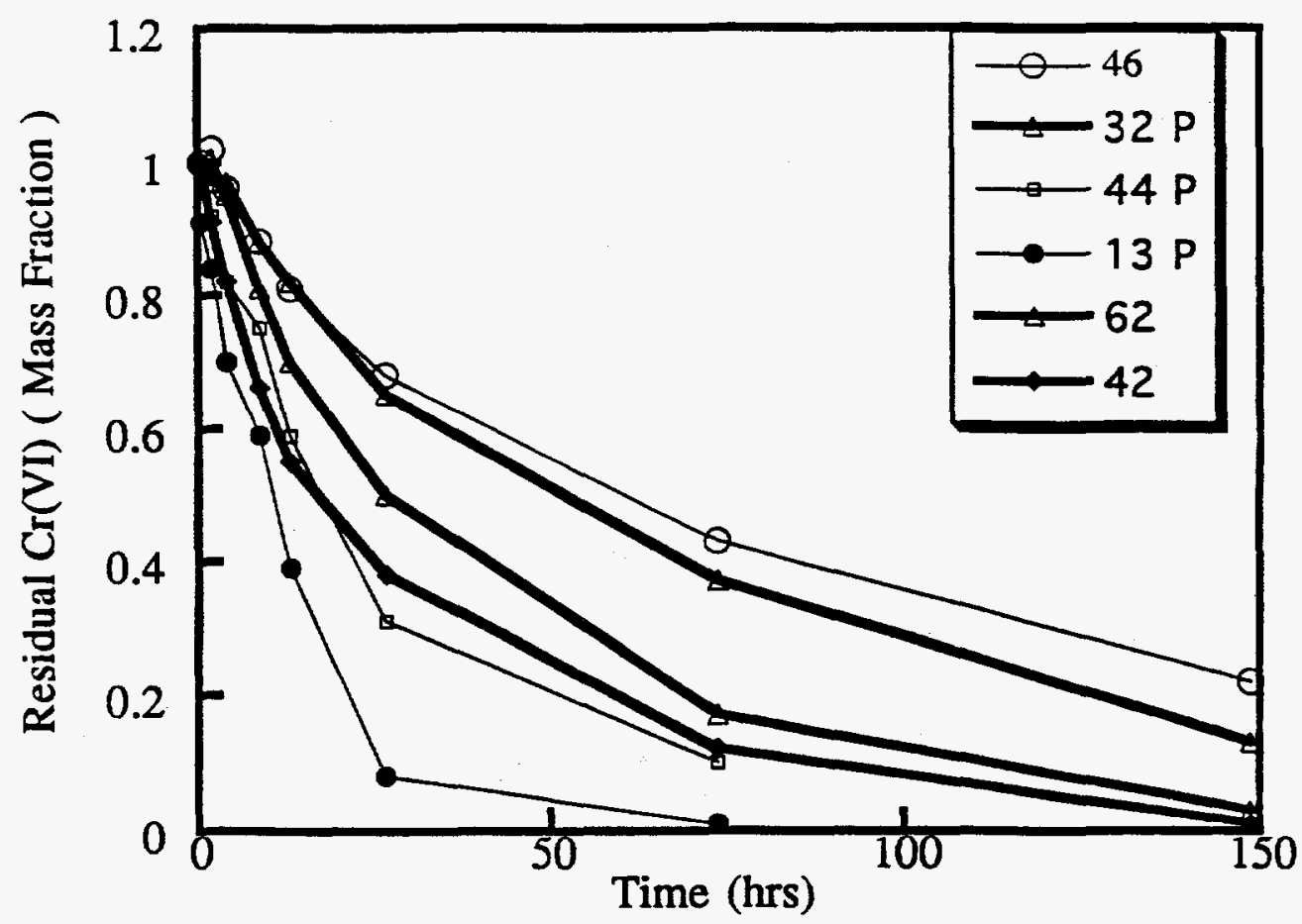

Figure 15. The fate of chromium (VI) in LWs: with and without added peat. 


\section{Simultaneous uptake of $\mathrm{Cu}$ (II) and $\mathrm{Cr}$ (VI) by LWs}

Since most of oil and gas wastewaters are known to contain both cationic and anionic heavy metals in the dissolved form, it was felt that a study of simultaneous uptake of cationic and anionic heavy metals would be helpful in the design and construction of a wetland treatment system for such waste waters. The experimental procedure used is identical to the one described earlier. Simultaneous uptake experiments were studied in duplicate. Two different molar ratios

$(\mathrm{Cu}(\mathrm{II} / \mathrm{Cr}$ (VI) ) of 3.8 and 0.46 were used. Water depth was maintained at the initial value of 5.5 inches and the $\mathrm{pH}$ was between 5.5 - 6.5 and did not change during the course of the experiment. The details of actual experimental conditions are given in Table 6. The results are shown in Figures 16 and 17.

Table 6. Details of experimental conditions.

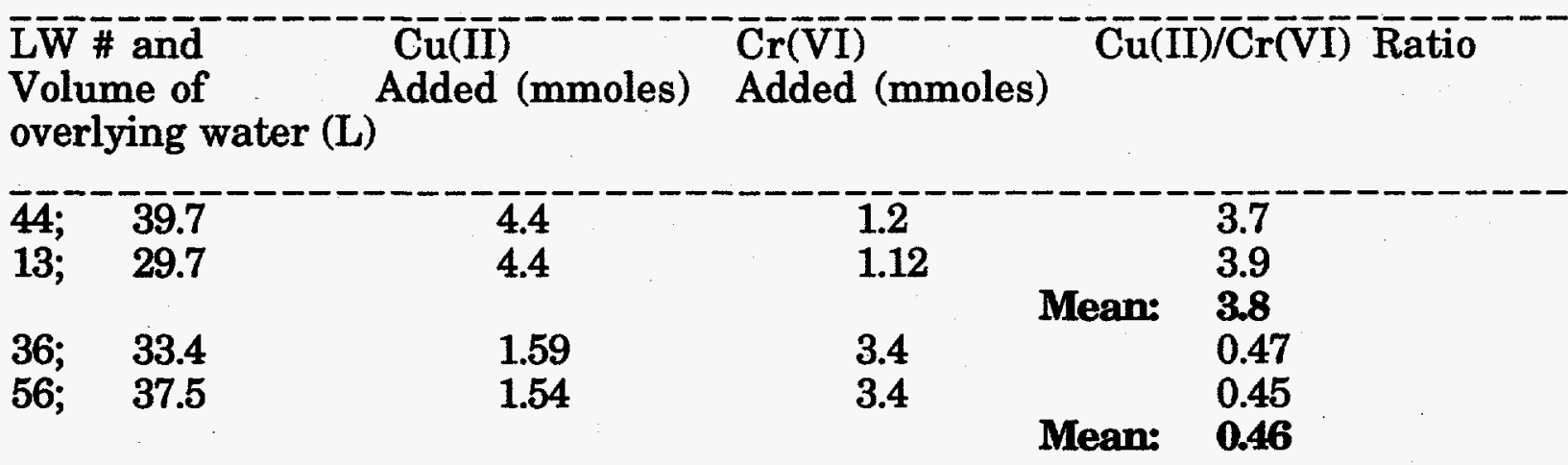

In Figure 16, the extent of removal of $\mathrm{Cr}$ (VI) by $\mathrm{LWs}$ in presence of $\mathrm{Cu}$ (II) ions is shown. It is worth noting that the uptake of $\mathrm{Cr}$ (VI) by LWs showed a similar exponential dependence with time when only $\mathrm{Cr}$ (VI) was present in the system. Thus, it would appear that the presence of $\mathrm{Cu}$ (II) ions had no measurable effect on Cr(VI) removal by LWs. This was verified by the fact that the first order rate of removal of $\mathrm{Cr}(\mathrm{VI})$ is nearly the same at high and low $\mathrm{Cu} / \mathrm{Cr}$ molar ratio. To quantify this effect, the data shown in Figure 16 were fitted to exponential functions of the form:

$$
[\mathrm{Cr}(\mathrm{VI})(\mathrm{t})] /[\mathrm{Cr}(\mathrm{VI})(0)]=\exp (-\mathrm{kt})
$$

and the respective rate constants were calculated. These are summarized in Table 7. 
Table 7. Kinetic constants for $\mathrm{Cr}$ (VI) uptake by $\mathrm{LWs}$ in presence of $\mathrm{Cu}(\mathrm{II})$.

\begin{tabular}{cccc}
\hline $\mathrm{Cu} / \mathrm{Cr}$ Ratio & $\mathrm{k}(\mathrm{hr}-1)$ & $\mathrm{t} 1 / 2(\mathrm{hrs})$ & $\mathrm{r}^{2}$ of the fit \\
\hline 3.67 & 0.0225 & 30.8 & 1.00 \\
3.92 & 0.0213 & 32.5 & 0.98 \\
0.46 & 0.0330 & 21.0 & 0.98 \\
0.45 & 0.0280 & 24.8 & 0.98 \\
\hline
\end{tabular}

It can be seen from Table 7 that low $\mathrm{Cu} / \mathrm{Cr}$ ratio leads to faster decay of solution phase $\mathrm{Cr}$ (VI) concentration. Since $\mathrm{Cr}(\mathrm{VI})$ is highly soluble at the operating $\mathrm{pH}$, the observed differences in the first order rate constants are attributed to variable characteristics of LWs. It can be concluded, however, that the average half life of $\mathrm{Cr}(\mathrm{VI})$ in LWs is of the order of 25 hours.

The removal of $\mathrm{Cu}(\mathrm{II})$ in presence of $\mathrm{Cr}$ (VI) shows a biphasic behavior; a rapid initial phase, followed by a slower second phase. These results are displayed in Figure 17. The data were fitted to a power law function of the form:

$$
[\mathrm{Cu}(\mathrm{II})(\mathrm{t})] /[\mathrm{Cu}(\mathrm{II})(0)]=\mathrm{a} \cdot\left(\mathrm{t}^{-\mathrm{n}}\right)
$$

where " $a$ " is a constant and " $n$ " is the power law exponent. The power law fit of the data is strictly empirical in nature which yields a useful, functional relationship between residual $\mathrm{Cu}$ (II) concentration vs. time. The details are shown in Table 8. 


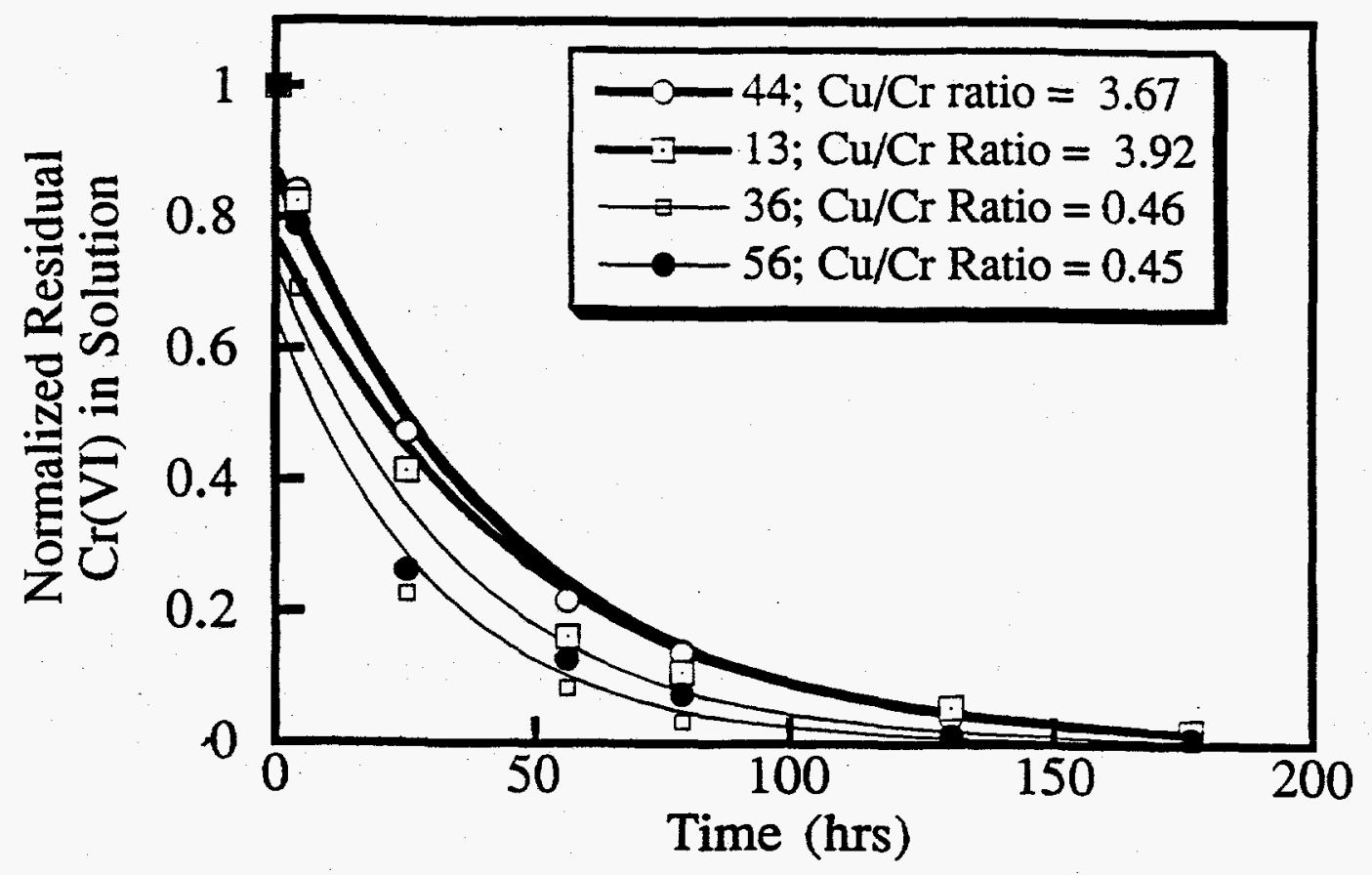

Figure 16. Removal of chromium (VI) by LWs in presence of copper ions: effect of copper/chromium ratio.

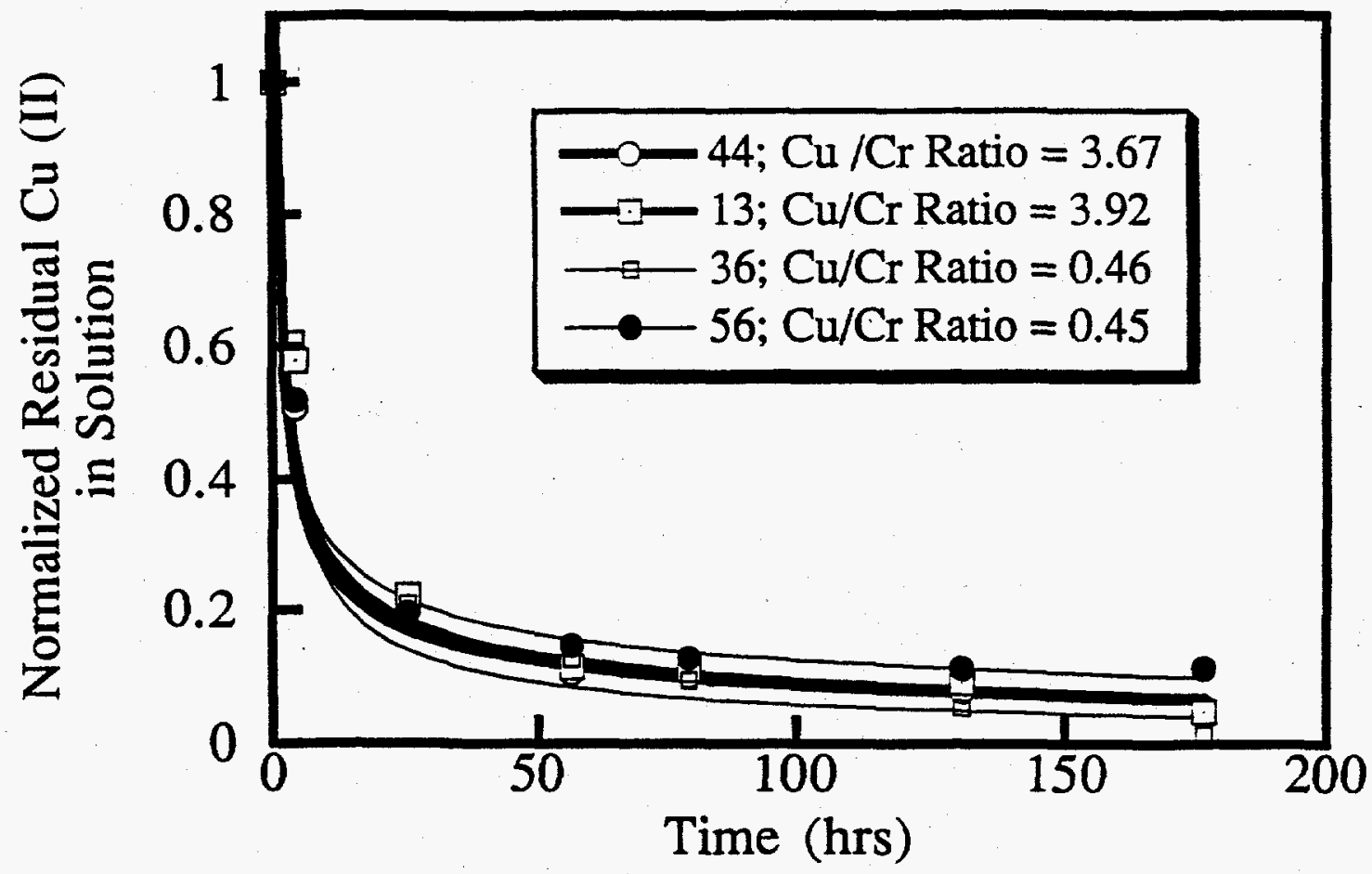

Figure 17. Removal copper (II) ions by LWs in presence of chromium (VI): effect of copper/chromium ratio. 
Table 8: $\quad$ Constants for $\mathrm{Cu}(\mathrm{II})$ Uptake by LWs in presence of $\mathrm{Cr}$ (VI):

$\begin{array}{cccc}\mathrm{Cu} / \mathrm{Cr} \text { Ratio } & \mathrm{n} & \mathrm{t} 1 / 2(\mathrm{hrs}) & \mathrm{r}^{2} \text { of the fit } \\ 3.67 & 0.50 & 2.86 & 0.99 \\ 3.92 & 0.50 & 3.24 & 0.97 \\ 0.46 & 0.63 & 3.30 & 0.94 \\ 0.45 & 0.40 & 3.14 & 0.99\end{array}$

Using the values of " a" obtained from the curve fit, half lives were calculated by inverting the above equation and these are listed in Table 8. The half lives for $\mathrm{Cu}$ (II) removal are approximately an order of magnitude lower than in the case of $\mathrm{Cr}$ (VI) removal. Secondly, the half life is independent of the initial $\mathrm{Cu}$ (II) concentration ( 30 and $6 \mathrm{ppm}$ ) or the $\mathrm{Cu} / \mathrm{Cr}$ ratio. This observation leads us to conclude that rapid removal of $\mathrm{Cu}$ (II) is most likely facilitated by adsorption onto suspended particulate matter in LWs by cation exchange. Hydrolysis of $\mathrm{Cu}$ (II) followed by precipitation would have shown a significant dependence on initial $\mathrm{Cu}$ (II) concentration, which was not observed experimentally.

Previously, we had identified three removal mechanisms for Cu(II), namely,

(1) Hydrolysis and precipitation

(2) Adsorption onto various components of a $\mathrm{LW}$

(3) Dispersion into the underlying pore space of a LW.

In light of the more extensive results discussed above, a biphasic removal mechanism appears more reasonable. Processes (1) and (2), to varying degrees, represent the first phase of $\mathrm{Cu}$ (II) removal while the slower phase is most likely dominated by diffusive dispersion of $\mathrm{Cu}$ (II) into the underlying pore water of a LW.

In summary, LWs can simultaneously remove $\mathrm{Cu}(\mathrm{II})$ and $\mathrm{Cr}(\mathrm{VI})$ from a binary, non-stoichiometric mixture of the two ions. The uptake of $\mathrm{Cr}$ (VI) in presence of $\mathrm{Cu}$ (II) by laboratory-type wetland systems follows first order kinetics with an average half-life of 25 hours irrespective of the initial $\mathrm{Cu} / \mathrm{Cr}$ ratio. On the other hand, $\mathrm{Cu}$ (II) removal is more complex with an average half-life of only 3 hours.

It was noted, during the course of these heavy metal uptake experiments, that the water samples drawn from the LWs contained small particles in suspension and that re-dispersion of these particles during the handling of the samples gave higher readings for metal ion concentration. The clear supernatant obtained after 
the particles had been allowed to settle out yielded, once again, lower values of residual metal ion concentration.

The implication of this qualitative finding is that fluid flow may transport contaminants out of a wetland unless sufficient time is allowed for fine particles in a wetland to settle before a given fluid element exits the wetland. Thus, the fluid flow has to be adjusted to effect fine particle settling. 


\section{Task 4. Design of a Field-scale Wetland System.}

The construction of wetland systems should be based upon sensible design guidelines that enable treatment goals to be achieved economically. Two categories are used to classify constructed wetlands; surface flow wetlands (SF) and subsurface flow wetlands (SSF). Both attempt to duplicate natural systems with stands of soft stemmed emergent plants such as cattails (Typha sp.), reeds (Phragmites sp.), bulrush (Scirpus sp.), sedges (Carex sp.), and grasses. The two systems differ in that surface flow wetlands correspond to a water table above ground level, while subsurface flow wetlands correspond to a water table just below ground level. Both types of wetland have the ability to treat polluted waters.

The choice of the constructed SF wetland alternative is normally based upon ancillary benefits, together with the ease of operation and possible residuals management. Part of the general perception of a wetland project has to do with whether or not humans and wildlife think it is a wetland. People associate surface water with the idea of a wetland, and waterfowl require open water for habitat.

The decision to construct a SSF treatment wetland is normally based upon one of two concerns; the need to avoid problems of exposure of humans and wildlife to the waters during treatment, and the need to reduce the vaporization of highly volatile compounds. The possible advantages of greater treatment efficiency are not evident in un-amended beds, and normally cannot overcome the added cost of the media. However, the media can be chemically designed to add to the performance potential. In a wetland system, metals and toxicants are passed primarily from the sediments to the sediment feeding birds and animals (32). The SSF wetland places these materials out of reach. An additional advantage of SSF systems is that having the water level below ground level minimizes mosquito breeding potential.

\section{Surface flow wetlands}

The design process for surface flow wetlands is deceptively simple in outline: determine if there is enough room to do the required treatment, size a shallow basin, and select a means of transporting the water to it. However, the nuances of each situation preclude a "cookbook" approach to design: no two constructed SF wetland systems are alike in all respects. The structure and function of wetland ecosystems are very complex, and require commensurately complex descriptions. There is some value in single number "rules of thumb," provided they are used only to gain a general idea of anticipated performance.

The activity of the wetland in pollutant removal is associated with the immersed sediments and biota. These reactive surfaces dominate the removal processes for all biologically active substances, due to the presence of biofilms and sorption sites on those surfaces. As a consequence, the rate of removal is strongly dependent on vegetation density. A bare soil, shallow pond has the minimum efficiency, while a densely vegetated, fully littered wetland of the same depth has a higher efficiency. The results of a water depth increase in a wetland depend on three factors: the 
distribution of bottom elevations in the wetland, the distribution of biotic material vertically above the wetland bottom, and the reactive potential of the materials themselves. In general terms, all immersed surfaces are capable of supporting biological activity, although the time scales of uptake may differ, and the degree of support may depend on the degree of decomposition of the biomaterial.

There are two ways to increase the hydraulic detention time of a wetland for a given flow of water: increase the total acreage and/or increase the water depth. In the regime of full inundation, deeper water provides no significant increase in the removal of a pollutant. The amount of contributing biomass is fixed, and therefore greater time is needed to reduce the pollutant in a larger volume of water. Conversely, increasing the wetland acreage at fixed depth does provide for more pollutant removal. This leads to the conclusion that the more effective method of increasing removal is to decrease the hydraulic loading rate (HLR). This has the effect of providing the intuitive increase in detention time without sacrificing efficiency to a depth increase.

The water volume fraction is normally quite high for SF wetlands, with values typically in the range of $0.90-0.95$. The depth chosen for SF wetlands is usually in the range $0.15-0.45$ meters. The seven to ten day hydraulic detention time range, therefore, translates to a typical range of hydraulic loading rates from 0.015 to 0.065 meters per day, with a central tendency of about 0.03 meters per day.

Rules of thumb provide the ability to quickly screen out a wetland alternative that has no chance of meeting project requirements. However, they are inadequate for final design. Final design should acknowledge the following items:

1. A set of pollution reduction targets.

2. Spatial variability of pollutant removal.

3. Hydraulic and meteorological constraints.

4. Internal depth and vegetation density patterns.

5. Internal flow and mixing.

6. Baseline wetland concentration values.

7. Seasonality.

8. Interaction with other treatment system components.

9. Nature of the regulatory requirements.

10. Acceptable level of risk.

These items should be jointly considered in the context of the determination of wetland dimensions.

Assembly of Design Data

\section{Characterization of the Water to be Treated}

The amount and timing of the water to be treated is the first and foremost item of the design basis. This information should include the possible seasonality of flows, and the anticipated progression of flows over the life of the design. 
Projecting flow estimates far into the future is risky, so it is necessary to be explicit about flow capacity at the time of design.

An important part of the overall definition of the system hydrology is a prediction of the rainfall and evapotranspiration patterns that will influence the project. Monthly values will be required for most point-source projects, but stormwater systems may require a definition of the frequencies of events and their magnitude and timing.

The information on water quantities and timing is assembled into the annual and monthly water budgets for the design, including any seasonal or event storage that may be necessary. This information is later linked to the computation of the expected reductions in pollutant concentrations.

The concentrations of the pollutants in the water to be treated are critical to the sizing process, and to the prediction of the wetland performance in the face of unknown future variations. A clear definition of the incoming water quality is essential, including the anticipated temporal distribution of concentrations.

\section{Treatment goals}

Most wetland treatment systems discharge to surface waters, and therefore must meet the conditions of a discharge permit. The conditions of the permit dictate the required performance of the wetland, and therefore govern its sizing.

Discharge is not always to surface waters, but possibly to groundwater, further treatment elements, or to reuse. Discharge in an increasing number of circumstances is directed to downstream wetlands, which are often a combination of surface and subsurface waters. These wetland water bodies are considered "waters of the United States," according to current definitions, and subject to appropriate regulations. However, the upstream (treatment) wetland is a considered to be part of the treatment system treatment system, and regulated according to a different set of rules. The design goals for the treatment wetland become the water quality and quantity desired for the management of the down stream, jurisdictional wetland. No matter what the receiving ecosystem or postwetland treatment element, proper design requires a clear statement of the required water quality leaving the wetland.

\section{Preliminary feasibility}

The attempt at SF wetland design addresses the general question of whether a constructed SF wetland fits the geographic and economic constraints of the problem. This involves first estimates of the necessary size, combined with a knowledge of land availability. Once the geographic constraints are resolved, the economics need to be addressed. 


\section{Preliminary sizing}

The goal of these calculations is to obtain a rough idea of the size of the wetland required, or whether in fact all the target water quality goals can be met. The general form of the model is:

$$
\ln \left(\frac{C_{e}-C^{*}}{C_{i}-C^{*}}\right)=-\frac{k}{q}
$$

where $\quad \mathrm{Ce}=$ outlet target concentration, $\mathrm{mg} / \mathrm{l}$

$\mathrm{Ci}=$ inlet concentration, $\mathrm{mg} / \mathrm{l}$

$\mathrm{C}^{*}$ = background concentration, $\mathrm{mg} / \mathrm{l}$

$\mathrm{k}=$ first order areal rate constant, $\mathrm{m} / \mathrm{yr}$

$\mathrm{q}=$ hydraulic loading rate, $\mathrm{m} / \mathrm{yr}$

Rearrangement, and a unit conversion, gives the area required for a particular pollutant:

$$
A=\left(\frac{0.0365 \cdot Q}{k}\right) \cdot \ln \left(\frac{F_{b}}{F_{b}-F_{e}}\right)
$$

where $\quad A=$ required wetland area, ha

$\mathrm{F}_{\mathrm{b}}=$ fraction reduction to background, $\mathrm{F}_{\mathrm{b}}=1-\mathrm{Cb}_{\mathrm{b}} / \mathrm{C}_{\mathrm{i}}$

$\mathrm{F}_{\mathrm{e}}=$ fraction reduction to target, $\mathrm{F}_{\mathrm{e}}=1-\mathrm{C}_{\mathrm{e}} / \mathrm{C}_{\mathbf{i}}$

$Q=$ water flow rate, $\mathrm{m}^{3 / \mathrm{d}}$

Both the hydraulic loading rate and the nominal detention time for a $30 \mathrm{~cm}$ depth may then be calculated from their definitions. The concentration of all pollutants is computed from the model, using the largest area:

$$
C_{0}=C^{*}+\left(C_{i}-C *\right) \cdot e^{\left(-\frac{k \cdot A}{0.0365 \cdot Q}\right)}
$$

where

$$
\mathrm{C}_{0}=\text { outlet concentration, } \mathrm{mg} / \mathrm{l}
$$

\section{Site characteristics}

In preliminary feasibility studies, three site characteristics bear further consideration. The first is site topography, which will determine the amount of earth moving, and thus influence the project cost. Topography also determines the need for pumps to move water to and from the site, again an important cost consideration. The second is site ownership. If the land must be purchased, a significant cost is incurred, including the market price of land and ancillary acquisition costs. The third consideration is the nature of the soils on the site. In many instances, the wetland will be required to be leak-tight, to protect 
groundwater. This is true even if the project is designed to recharge groundwater as its method of discharge. If the soils on the site are permeable, then a liner will be required, and hence contribute to the project cost. This is usually a significant cost if native materials are not available onsite. At the feasibility level, the need for a wetland lining is estimated, and the cost factors increased accordingly.

\section{Preliminary economics}

The purpose of the preceding steps is to determine if the wetland concept bears further investigation as an alternative for solving the water quality problem. If the technology can do the job, and the land is available, then economic factors are checked.

Two items often run up project costs: elaborate water control structures and a perceived need to plant the wetland. The former originate from over-engineering and from the need to provide and house expensive monitoring and control equipment. The latter results from a desire to propagate a selected suite of plant species in a short period of time. These items can often be minimized through recognition of the passive, low-tech, self-sustaining character of the most successful projects.

Wetland systems have very low intrinsic operating and maintenance costs, including pumping energy, compliance monitoring, maintenance of access roads and berms, and mechanical component repair. These basic costs are much lower than those for competing concrete and steel technologies, by a factor of two to ten. However, ancillary research costs, which occur at the directive of the regulatory agencies, have frequently canceled out this large potential advantage. Operating and maintenance costs should be capitalized, and added to the construction costs to obtain a present worth for the entire project. Further economic considerations may emerge during final design.

\section{Detailed conceptual design}

If there are positive indications of treatment potential, evidenced from results for analogous compounds, or field or laboratory wetland microcosms, then a pilot treatment project is in order. In no case should short term microcosm or mesocosm results be used as the sole basis of a wetland design. These have been notoriously bad predictors of the performance of full scale ecosystems. The reasons are many: the hydrology is wrong, the proportion of edge effects is too large, environmental factors are constrained or absent, the study period does not carry on to the sustainable limit, short term capacities are included, species composition changes are constrained. The value of such small scale experiments lies in the understanding of process details.

Accordingly, pilot wetlands should be not less than $500 \mathrm{~m}^{2}$, and should be run long enough to pass the startup transients -- normally one to two years. The subsequent data acquisition period should span all seasons, and preferentially more than once. Key design variables include hydraulic loading rate, inlet concentration, depth and vegetation density. The cost of complete pilot projects is 
high, and has therefore been preceded in some instances by a pilot demonstration project.

\section{Caps versus averages}

All treatment technologies possess a spectrum of effluent concentrations, because of unpredictable, stochastic driving forces. Therefore, in addition to the mean effluent concentration (which may vary in a deterministic way with temperature and loading) there is an associated band width of concentration. Regulations may constrain both the mean and the maximum of the band, via specification of a limit on the maximum daily, weekly or monthly value; together with a limit on the average annual value. In this phase of design, care must be taken to select the most restrictive of multiple averaging tests given by the regulation.

\section{Final sizing and layout}

Two major tasks remain in the conceptual design phase: sizing for the anticipated detailed annual patterns of wastewater parameters, seasonal variables and seasonal regulatory requirements; and determination of the wetland configuration. The first requires a more detailed exploration of predicted performance, while the second involves considerations of water conveyance and control of flow. Detailed area calculations are made to determine a wetland area which will meet the design requirements at all times. The primary calculation tools are the $\mathrm{k}-\mathrm{C}^{*}$ mass balance model (equation 9) and the water budget.

There are two fundamentally different sources of variability in the performance of the treatment wetland: variations in the inputs and variations within the ecosystem. The first may be quantified from previous information, such as design specifications of the wastewater and climatic data. It is this category that is explored at this stage of design. The second category has to do with stochastic processes within the ecosystem. In sum, these are reflected in variability in the model parameters. It is possible to list many causative factors: algal blooms, insect attacks, vertebrate herbivory, and species competition. But predictive models of these phenomena are beyond the present state of our knowledge, and thus their cumulative effects on water quality remain as a stochastic variation in the parameters of the simple $\mathrm{k}-\mathrm{C}^{*}$ model.

Monthly calculations are typically required whenever temporal water quantity management is included as part of a design. Storage pond-wetland combinations used in northern climates are one such circumstance. Other strategies include alternating use of wetland cells, and bypassing of extreme flows (off-lining).

\section{Presumed state of mixing}

The premise in global parameter estimation has been that of plug flow, which has been adopted on the premise of conservatism. If that assumption is to be modified, it is in the final sizing calculation. 
If the designer wishes to take some credit for the acknowledged partial mixing in known wetlands, he does so by adjusting the rate constant upward, utilizing the presumed imperfect mixing model. One such presumption is that SF wetlands behave more like $\mathrm{N}$ well mixed units in series. Then for the estimation of the $\mathrm{k}$ value:

$$
\frac{C_{e}-C^{*}}{C_{i}-C^{*}}=e^{\left(-\frac{k_{p f}}{q}\right)}=\left(1+\frac{k_{N}}{N \cdot q}\right)^{-N}
$$

where

$$
\begin{aligned}
\mathrm{C}_{\mathrm{e}} & =\text { measured outlet concentration, } \mathrm{mg} / \mathrm{l} \\
\mathrm{C}_{\mathrm{i}} & =\text { measured inlet concentration, } \mathrm{mg} / \mathrm{l} \\
\mathrm{C}^{*} & =\text { background concentration, } \mathrm{mg} / \mathrm{l} \\
\mathbf{k}_{\mathrm{pf}} & =\text { first order areal rate constant, } \mathrm{plug} \text { flow, } \mathrm{m} / \mathrm{yr} \\
\mathbf{k N}_{\mathrm{N}} & =\text { first order areal rate constant, } \mathrm{N} \text { CSTRs, } \mathrm{m} / \mathrm{yr} \\
\mathrm{N} & =\text { number of well mixed units assumed } \\
\mathrm{q} & =\text { measured hydraulic loading rate, } \mathrm{m} / \mathrm{yr}
\end{aligned}
$$

Therefore,

$$
k_{N}=N q\left(e^{\left(\frac{k_{p f}}{N \cdot q}\right)}-1\right)
$$

Convevance: aspect ratios, head loss and linear velocity

The wetland area selected by the above procedures may be configured in many ways in its plan view; i.e., many different length to width ratios. As the length to width ratio is increased, the linear velocity increases, and the head loss increases. At some point, the head loss will produce an inlet water depth that is unacceptably large. There has also been some conjecture in the literature that long narrow wetlands behave closer to plug flow, but tracer data do not support that speculation.

\section{Water velocity}

As a conservative interim design criterion, it is recommended that linear velocity be kept below a value which would re-suspend $15 \mu \mathrm{m}$ particles. That number is approximately $1000 \mathrm{~m} / \mathrm{d}$. However, it is well to bear in mind that existing SF wetlands operate at velocities lower than this, mostly below $100 \mathrm{~m} / \mathrm{d}$, and hence there is no field test of the criterion. However, it may be noted that virtually all SF wetlands do trap sediments effectively.

\section{Conceptual compartmentalization}

At this point in the design procedure, the size and shape limits for the wetland system have been determined. There is next a need to set the 
compartmentalization of the system. Multiple flow paths are to be recommended, to ensure operational flexibility. Although maintenance is normally infrequent, there can be reasons for accessing the wetland interior.

There are not "absolute" rules for design for high areal efficiency. Some general ideas are:

1. Avoid blind spots in corners.

2. Provide flow straightening berms interior to an individual wetland cell.

3. Re-establish flow distribution at intermediate points in a flow path.

4. Maintain good bottom uniformity during construction and startup: do not allow topographic channels parallel to flow.

The above considerations lead to a system configuration that may generally be described as "multiple strings of beads."

\section{Plants and planting}

If the wetland is to be planted, the cost and availability of plant materials must be addressed early in the design process. The option of establishing an onsite wetland plant nursery must be decided very early, because mature, two year old plants are preferred. These have the energy reserves to survive the transplanting operation. Consequently, the establishment of the nursery must be complete well in advance of other construction.

Another option is to allow natural regrowth of the wetland basins. In southern climates, this process is complete within one growing season, but may require two or more seasons in northern climates. In either climate, the option of transplanting will accelerate the establishment of vegetation. The design decision is based on economics and the regulatory requirements on startup. A one year delay in the imposition of permit requirements allows for natural regrowth, and can save a considerable amount of money.

From the standpoint of system resiliency, the wetland should probably contain a diverse mix of macrophyte species, and thus be in a position to accommodate changes in water quality and timing that may occur. In other words, a polyculture is preferable to a monoculture. Most SF treatment wetlands undergo a process of alteration after an initial planting, with the more robust species gaining dominance: cattails, reeds, and bulrushes. However, in ultra polishing systems, with very high water quality, a very diverse species composition may develop. 


\section{Subsurface flow wetlands}

The general concepts for SSF wetland design are not far different from those for SF wetlands, but the details are quite different in some instances. Most importantly, the regressions and rate constants for pollutant removal are different, and the hydraulics are different. The SSF wetland is viewed as a vertically integrated unit, consisting of media, water, and plants.

The first task is assembly of design data. It is necessary to carefully define the quantity and quality of the water to be treated, and the goals of the treatment. The next task is determination of preliminary feasibility, which follows the same pattern as for SF wetlands.

Gravel beds are more costly on an areal basis than SF wetlands. However, they possess certain advantages, in terms of larger rate constants, and in terms of nuisance reduction. Therefore, economics must be evaluated in the context of ancillary benefits and values. The cost of the media is a large fraction of the total cost of gravel bed wetlands, and this added expense must be weighed against the potential advantages of the subsurface flow system.

The life expectancy of SSF systems is limited by the accumulation of mineral solids in the pore space. Blockage by degradable biosolids is also expected, but this is accounted for in hydraulic design.

\section{Detailed conceptual design}

One of the historical difficulties with SSF wetlands has been the construction of projects based on rules of thumb and personal whims, rather than based on sound and thorough analysis of available data. The need for pilot projects also applies to SSF wetlands. An important addition is the need to carefully consider the performance and difficulties associated with operation in cold climates. A second addition is consideration of the tailoring of the media to provide added sorption capacity for metals.

Just as for SF wetlands, the premise in global parameter estimation has been that of plug flow, which has been adopted on the premise of conservation. There is clearly not plug flow in SSF systems, as has been repeatedly demonstrated in tracer tests.

The SSF wetland area may be configured in many different length to width ratios. As the length to width ratio is increased, the linear velocity increases, and the head loss increases. At some point, the head loss will produce overland flow.

There has also been some conjecture in the literature that long narrow wetlands behave closer to plug flow, but tracer data do not support that speculation. As was the case for SF wetlands, it is necessary to avoid gross areal inefficiency by correct selection of inlet distribution and outlet collection. A larger length to width ratio promotes greater gross areal efficiency, but will not prevent pocket and profile mixing. The planar area of a wetland is selected to provide the correct hydraulic 
loading, and that in turn sets the detention time via the selection of the bed depth. Since the bed depth is typically 0.5 meters, there remain only two questions: what length to width ratio, and what media size?

Because the choice of an SSF wetland is normally predicated upon the desire to keep the water below ground (rather than upon economics), the design strategy should be to select both the media size and the $\mathrm{L}: \mathrm{W}$ ratio to control the bed hydraulics.

Therefore, these two variables are selected to meet these design criteria:

A. Anticipated flows must pass through the bed without overland flow or flooding.

B. Anticipated flows must pass through the bed without stranding the plants above water.

C. Operation should remain acceptable in the likely event of changing hydraulic conductivity.

D. The bed should be drainable.

E. The bed should be floodable.

F. Water levels within the system should be fully controllable through the use of inlet and outlet structures.

G. The configuration must fit the site, in terms of project boundaries and in terms of hydraulic profiles.

The case of a rectangular bed may be reduced to a fairly simple set of criteria to be met. The exit water level is presumed to be controlled at $90 \%$ of the bed depth. The maximum freeboard is $10 \%$ of the bed depth. When profiles are computed over the full range of values of design variables, the region in which these constraints are met may be identified. The results may be summarized in the constraints:

$$
\begin{gathered}
\frac{(\delta / \mathrm{L})}{\mathrm{S}_{\mathrm{b}}}>10 \\
\frac{(\mathrm{q} / \mathrm{k})}{(\delta / \mathrm{L})^{2}}=\frac{(\mathrm{q} / \mathrm{k})}{\mathrm{R}_{\mathrm{y}}^{2}}<0.1
\end{gathered}
$$

where $\quad \mathbf{H}=$ bed depth, $\mathrm{m}$

$\mathrm{k}=$ hydraulic conductivity of the bed, $\mathrm{m} / \mathrm{d}$

$L=$ bed length, $\mathrm{m}$

$\mathrm{q}=$ hydraulic loading rate, $\mathrm{m} / \mathrm{d}$ 


$$
\begin{aligned}
& R_{y}=\text { longitudinal bed aspect ratio, } d / L \text {, dimensionless } \\
& \mathrm{Sb}_{\mathrm{b}}=\text { bed slope, dimensionless } \\
& \delta=\text { thickness of the bed media, } \mathrm{m}
\end{aligned}
$$

These constraints must be met for all anticipated operating conditions, including initial and clogged conductivity, and the range of operating flows expected.

\section{Selection of plants}

A gravel bed will require planting, because seed banks are typically lacking, and the media is not optimal for germination. If a portion of the bed remains flooded, a litter layer may develop that is conducive to germination of wetland plant seeds, thus permitting invasion.

The presence of macrophytes is important for many pollutant removal functions. However, the question of which plant may be best is not yet known. It is, therefore, not surprising that vegetation has been chosen in the past on the basis of hardiness, cost, and local perceptions rather than treatment ability.

\section{Summary}

Design techniques are similar for SF and SSF systems. Sizing is the first step in the design process. ThE constants used should be gathered through experimentation, or from the literature. For most parameters, the values of the rate constants are not greatly different between SF wetlands and SSF wetlands. The gravel media of a SSF system is typically a large added cost compared to SF pricing, so SSF systems are generally more expensive. The additional cost may be justifiable in terms of ancillary considerations, such as mosquito production, human contact, and wildlife protection.

The compartmentalization and aspect ratios are set, with due attention to the hydraulic constraints and site constraints. The hydraulics are of greater concern for the SSF wetland, because a premium price is to be paid to keep water below ground. Loading and dimensional criteria must be met if flooding is not to occur, and dryout is to be avoided. To that end, the length to width ratio and media size are selected for the SSF wetland. For SF systems, structures are selected, a plant establishment strategy determined, and water conveyance is set.

The project is then ready for a more detailed economic estimate, which may require techniques that acknowledge the features of wetland systems. 


\section{Acknowledgments}

Prof. R. H. Kadlec has been the project director of the present study. He is a professor of Chemical Engineering at the University of Michigan, Ann Arbor, MI. His professional work has been primarily concerned with the implementation of wetland systems for water pollution control. He has been a principal designer of over twenty wetland treatment systems, and has conducted feasibility studies for many others. He has been actively involved in wetland research for more than two decades, and has carried out field investigations of physical, chemical, and biological processes in wetlands. Prof. Kadlec is recognized internationally for his scholarly contributions to wetland science and engineering.

Dr. Keeran Srinivasan has been the project manager of the present study. He is an Associate Research Scientist, a senior research position, in the Department of Chemical Engineering at the University of Michigan, Ann Arbor, MI. He has been involved since 1983 in the use of microseparation processes for the removal of toxic organics and heavy metals from wastewater streams. He holds two U. S. patents on different formulations of surfactant-modified clays for industrial wastewater treatment and has several publications in the area of microseparation processes for industrial wastewater treatment. He is currently working on:

(1) Treatment of "mixed" hazardous waste

(2) Role surfactants in enhanced bioavailability during in situ bioremediation.

Messrs. Keith Sandhum and Ravi Shanker, graduate students in this department, worked on various aspects of the present study and both graduated with Masters degrees in chemical engineering.

Mr. Tim Werner, a Ph. D. student of Prof. Kadlec, contributed to the studies on the uptake of heavy metals by laboratory-type wetland system (LWs) and he is expected to graduate in 1995.

Ms. Rachel Adams and Ms. Shelley Rivette, under graduate students in this department assisted ably on this project; the former on the modeling of the fate of phenol in LWs and the latter with extensive laboratory work and many assays. Both Ms. Adams and Ms. Rivette have since graduated. 


\section{Bibliography}

(1) Kadlec, R. H. and Keolian, G. A.. "Metal Ion Exchange on Peat." In: The Relationship of Water with Peat. C. H. Fuchsman, Ed., May 1986. Elsevier, pp. 61-94.

(2) Eger, P., Lapakko, K. and P. Otterson. "Trace Metal Uptake by Peat: Interaction of a White Cedar Bog and Mining Stockpile Leachate," Proc. 6th Int. Peat Cong., Duluth, MN, 1980.

(3) Hammer, David E. and Kadlec, Robert H. "Orthophosphate Adsorption on Peat." 6th International Peat Congress, Duluth, Minnesota, 1980.

(4) Kadlec, R. H. and H. H. Alvord, Jr. "The Role of Wetlands in Agricultural Non-Point Pollution Control," Paper presented at Conf. on Biogeochemical Cycling in Wetlands, LSU, Feb. 1991.

(5) Kadlec, R. H. "Denitrification in Wastewater Wetlands," Paper presented at WPCF Conf., Dallas, TX, 1989.

(6) R. H. Kadlec and Keeran R. Srinivasan: 1st Quarterly Report, U. S. DOE, PETC, August, 1992.

(7) R. H. Kadlec and Keeran R. Srinivasan: 2nd Quarterly Report, U. S. DOE, PETC, November, 1992.

(8) R. H. Kadlec and Keeran R. Srinivasan: 3 rd Quarterly Report, U. S. DOE, PETC, February, 1993.

(9) R. H. Kadlec and Keeran R. Srinivasan: 4th Quarterly Report, U. S. DOE, PETC, May, 1993.

(10) R. H. Kadlec and Keeran R. Srinivasan: First Summary Annual Report, U. S. DOE, PETC, July, 1993.

(11) Keeran R. Srinivasan and Henry Y. Wang: Proceedings of the Joint Symposium on Environmental Engineering by Canadian and American Societies of Civil Engineering, Montreal, Quebec, Vol. II, 1111( 1993) June, 1993.

(12) R. H. Kadlec and Keeran R. Srinivasan: 5th Quarterly Report, U. S. DOE, PETC, October, 1993.

(13) C. Polprasert and N. P. Dan: " Phenol Removal in Model Constructed Wetlands Located in the Tropics ", Proc. WEFTEC'94, 67th Annual Conference and Exposition, Chicago, Illinois, Vol 8, Part 1, p 45 - 55 (1994). 
(14) R. H. Kadlec and Keeran R. Srinivasan: 6th Quarterly Report, U. S. DOE, PETC, December, 1993.

(15) R. H. Kadlec and Keeran R. Srinivasan: 7th Quarterly Report, U. S. DOE, PETC, April, 1994.

(16) R. H. Kadlec and Keeran R. Srinivasan: 8th Quarterly Report, U. S. DOE, PETC, June, 1994.

(17) R. H. Kadlec and Keeran R. Srinivasan: Second Summary Annual Report, U. S. DOE, PETC, July, 1994.

(18) Jackson, J. "Man-Made Wetlands for Wastewater Treatment: Two Case Studies," in: Constructed Wetlands for Wastewater Treatment, Lewis, Chelsea, MI 1989.

(19) Litchfield, D. K. and D. D. Schatz " Constructed Wetlands for Wastewater Treatment at Amoco Oil Company's Mandan, North Dakota, Refinery," in: in: Constructed Wetlands for Wastewater Treatment, Lewis, Chelsea, MI 1989.

(20) Litchfield, D. K. " Constructed Wetlands for Wastewater Treatment at Amoco Oil Company's Mandan, North Dakota, Refinery," in: Constructed Wetlands for Water Pollution Control, Pergamon, New York, 1990.

(21) Duda, P. Chevron Oil Company, Richmond, CA, Personal communications and site visit, 1989.

(22) Honig, R. "Tenneco's Use of a Rock-Reed Filter at a Natural Gas Pipeline Compressor Station," Poster Session Paper at Conference on Constructed Wetlands for Wastewater Treatment, Chattanooga, TN, 1988.

(23) H. Scott Fogler, and Keeran R. Srinivasan: " Modified Clay Adsorbents ", U. S. Patent \# 4740488, ( April 26, 1988).

(24) Srinivasan, Keeran, R. and Fogler, H. Scott: " Use of inorgano-organo-clays in Industrial waste water Treatment. Part I. Structural Aspects. ", Clays \& Clay Minerals, 38(3), 277 (1990).

(25) Srinivasan, Keeran, R. and Fogler, H. Scott: " Use of inorgano-organoclays in Industrial waste water Treatment. Part II. adsorption of Benzopyrene and chlorophenols", Clays \& Clay Minerals,_38(3), 287, (1990).

(26) H. Scott Fogler, and Keeran R. Srinivasan: " Use of Inorgano-organo-clays in Wastewater Treatment ", U. S. Patent \# 4916095, ( April 10, 1990).

(27) Keeran R. Srinivasan and H. Scott Fogler: "Use of Inorgano-organo-Clays in the Treatment of Coal Conversion Waste Waters," Proc. 1990 International Symposium on Dioxin and Other Pollutants, held at Bayereuth, Fed. Republic of Germany, September, 1990. 
(28) Akzo Chemie America: Bulletin 85-1, "Specification and Properties of DUOMEEN Diamines and Diamine Salts", An Armak Chemical Publication, (1985).

(29) J. R. Gulley and P. G. Nix: "Wetland Treatment of Oil Sands Operation Wastewater" ( Private Communication from authors to Prof. Kadlec, 1993).

(30) Standard Methods for the Examination of Water and Waste water: 16th Edition, a Publication of APHA, AWWA, and WPCF, Published by APHA, Washington, D. C., pp 556-570 ( 1985)

(31) A. Imai and E. F. Gloyna: Water Research, 24(9), 1143-1150 (1990).

(32) Saunders, F. Personal communication (1993). 


\section{Index}

\section{Key Word}

$\beta$-naphthoic acid

Cr(VI)

$\mathrm{Cu}(\mathrm{II})$

Detailed Design

Field-scale Wetland System

Final Sizing and Lay out

Hectorite-CBDA-DT (HCDT)

Laboratory-type Wetlands

Literature Review

MONT-DT

Phenol

Selection of Plants

Site Characteristics

Soil Components

Subsurface Flow Wetlands

Surface Flow Wetlands

Treatment Goals

Water Velocity

Wetland Amendments

Wetlands: Overview
Page No.

$13,16,18,20$

$13,25,27$

$13,25,27$

33,36

29

33

11

7

7

12

$16,19,20,21,22,23$

37

32

8

35

29

31

34

11

1 


\section{Appendix I}

Major Literature Sources on Wetlands to Improve Water Quality.

FOCUS ON POLLUTION CONTROL

[39] Wetland Systems in Water Pollution Control, Water Science and Technology, Vol. 29, No. 4, 1994, 336 pp.

[38] Proceedings of the Fourth International Conference on Wetland Systems for Water Pollution Control, Guangzhou, China, Chuncai Jiang, Editor, 1994, 798 pp.

[37] Global Wetlands: Old World and New, W.J. Mitsch, Editor, Elsevier, Amsterdam, 1994, $967 \mathrm{pp}$.

[36] Pflanzenkläranlagen: Abwasserreinigung mit Bepflantzen Bodenkörpern, $B$. Saurer, Editor, Wasserwirtschaft Land Steiermark, Graz, Austria, 1994, 172 pp.

[35] Constructed Wetlands for Water Quality Improvement, G. A. Moshiri, Editor, Proceedings of an International Symposium, Lewis Publishers, Chelsea, MI, 1993, $632 \mathrm{pp}$.

[34] Database: North American Wetlands for Water Quality Treatment, Phase II Report, R. L. Knight, R. W. Ruble, R. H. Kadlec and S. C. Reed, prepared for USEPA, September, 1993, 824 pp. Diskette available from D. S. Brown, USEPA, Risk Reduction Engineering Laboratory, Cincinnati, OH 45268.

[33] General Design, Construction, and Operation Guidelines: Constructed Wetlands Wastewater Treatment Systems for Small Users Including Individual Residences, Technical Report TVA/WM--93/10, Tennessee Valley Authority, Chattanooga, TN, May, 1993, 42 pp.

[32] Subsurface Flow Constructed Wetlands for Wastewater Treatment: A Technology Assessment, USEPA Office of Water, Report EPA 832-R-93-001, July, $1993,72 \mathrm{pp}$.

[31] Wetland Systems in Water Pollution Control, Proceedings of an International Symposium, Sydney, Australia, 1992, ca. 600 pp.

[30] Design of Stormwater Wetland Systems, T. R. Schueler, Metropolitan Washington Council of Governments, Washington, DC, 1992, 133 pp.

[29] The Use of Wetlands for Controlling Stormwater Pollution, E. W. Strecker, J. M. Kersnar, E. D. Driscoll, and R. R. Horner, EPA/600, Terrene Institute, Wash. D.C., 1992, 66 pp +230 pp Appendix. 
[28] Ecological Engineering for Wastewater Treatment, C. Etnier and B. Guterstam, eds., Bokskogen, Gothenburg, Sweden, 1991, 365 pp.

[27] Spildevandsrensning i rodzoneanlæg, $H-H$. Schierup, $H$ Brix, and B. Lorenzen, Botanical Institute, Aarhus University, Denmark, 87 pp.

[26] An Inventory of Constructed Wetlands used for Wastewater Treatment in the United States, S. C. Reed, prepared for USEPA, March 1990, 163 pp.

[25] Moerassen voor de Zuivering van Water (Wetlands for the Purification of Water), Post Academic Course, published as The Utrecht Plant Ecology News Report, University of Utrecht, Lange Nieuwstraat 106, 3512 PN Utrecht, The Netherlands, No. 11, October 1990, 269 pp., (about 50\% in English).

[24] Behandlung von häuslichen Abwasser in Pflanzenbeeten, ATV, Gesellschaft zur Föderung der Abwassertechnik e.V., Postfach1160, Markt 71, D-5205 St. Augustin 1, Germany. English translation of this design guideline document available, $1989,12 \mathrm{pp}$.

[23] European Design and Operations Guidelines for Reed Bed Treatment Systems, P. F. Cooper, Editor, prepared by EC/EWPCA Emergent Hydrophyte Treatment Systems Expert Contact Group, Water Research Centre, Swindon, UK, $1990,33 \mathrm{pp}$.

[22] Constructed Wetlands in Water Pollution Control, P. F. Cooper and B. C. Findlater, Editors. Pergamon Press, London, 1990, 605 pp.

[21] Water Pollution Control Federation. Manual of Practice: Natural Systems, Wetlands Chapter. February 1990, MOP FD-16 WPCF, 270 pp.

[20] Water: Laws and Management, F. E. Davis, Ed., AWRA, Bethesda, MD, $1989,>600 \mathrm{pp}$.

[19] Wetlands: Concerns and Successes, D. W. Fisk, Ed., AWRA, Bethesda, MD, 1989, 565 pp.

[18] Constructed Wetlands for Wastewater Treatment, Conference Proceedings, D. A. Hammer, Editor, Lewis Publishers, Chelsea, MI , 1989, 831 pp.

[17] Design Manual: Constructed Wetlands and Aquatic Plant Systems for Municipal Wastewater Treatment, USEPA 625/1-88/022, September 1988, 83 pp.

[16] Reed, S. C., Middlebrooks, E. J. and R. W. Crites. Natural Systems for Waste Management and Treatment, McGraw-Hill, NY, 1988, 308 pp.

[15] The Ecology and Management of Wetlands, D. D. Hook \& Others, Eds., Timber Press, Portland, OR, 1988, 992 pp.

[14] Report on the Use of Wetlands for Municipal Wastewater Treatment and Disposal, USEPA 430/09-88-005, October 1987. 
[13] K. R. Reddy and W. H. Smith, eds. Aquatic Plants for Water Treatment and Resource Recovery, Magnolia, Orlando, 1987, 1032 pp.

[12] Kaynor, E. R., P. J. Godfrey and J. Benforado. Ecological Considerations in Wetland Treatment of Municipal Wastewaters, Van Nostrand, 1985, $473 \mathrm{pp}$.

[11] Freshwater Wetlands for Wastewater Management Handbook, USEPA 904/985-135, September 1985, 507 pp.

[10] The Ecological Impacts of Wastewater on Wetlands: An Annotated Bibliography, USEPA 905/3-84-002, Feb., 1984, 257 pp.

[9] Hyde, H. C., Ross, R. S. and F. Demgen. Technology Assessment of Wetlands for Municipal Wastewater Treatment, USEPA 600/2-84-154, NTIS No. PB 85106896, November 1984, $98 \mathrm{pp}$.

[8] Hammer, D. E. and R. H. Kadlec. Design Principles for Wetland Treatment Systems, USEPA 600/2-83-026, 1983, 243 pp.

[7] Phase I Report: Freshwater Wetlands for Wastewater Management, USEPA 904/9-83-107, 1983.

[6] The Effects of Wastewater Treatment Facilities on Wetlands in the Midwest, USEPA 905/3-83-002, 1983, $377 \mathrm{pp}$.

[5] Eisenberg, D. M. and J. R. Benneman. An Overview of Municipal Wastewater Aquaculture, USEPA, Draft Final Report, Contract No. DM41USC252(C), March $1982,84 \mathrm{pp}$.

[4] Chan, E., Bursztynsky, T. A., Hantsche, N., and Y. J. Litwin. The Use of Wetlands for Water Pollution Control, USEPA 600/2-82-036, September 1982, 261 pp.

[3] Proceedings of the Seminar on Aquaculture Systems for Wastewater Treatment, R.K. Bastian and S.C. Reed, Eds., USEPA Publication No. MCD-67, September 1979, 485 pp.

[2] Wetland Functions and Values: The State of Our Understanding, P. E. Greeson, J. A. Clark and J. E. Clark, Eds.,AWRA, Minneapolis, MN, 1979, 674 pp.

[1] Freshwater Wetlands and Sewage Effluent Disposal, Proceedings of NSF/RANN Conference, D. L. Tilton, R. H. Kadlec, and C. J. Richardson, Eds., The University of Michigan, Ann Arbor, Michigan, May 10-11, 1976, NTIS PB259305, $343 \mathrm{pp}$. 
WETLANDS: SOME GENERAL REFERENCES

[9] Global Wetlands: Old World and New, W.J. Mitsch, Editor, Elsevier, Amsterdam, 1994, 967 pp.

[8] Applied Wetlands Science and Technology, D.M. Kent, Editor, Lewis Publishers, Boca Raton, FL, 1994, 436 pp.

[7] Freshwater Wetlands and Wildlife, R. R. Sharitz and J. W. Gibbons, eds., U.

S. Department of Energy, NTIS \#DE90005384, 1989, 1265 pp.

[6] Wetlands Ecology, Productivity and Values, S. K. Majumdar, F. J. Brenner, R. P. Brooks, and R. W. Tiner, Eds., Pennsylvania Academy of Science, Easton, PA, 1988,395 pp.

[5] The Ecology and Management of Wetlands, D. D. Hook, Ed., Croom Helm, Beckenham, UK, Two Volumes,1987, 988 pp.

[4] Wetlands, Mitsch, W. J. and J. G. Gosselink, Van Nostrand Reinhold Co., New York, 1993, 722 pp.

[3] Freshwater Marshes, M. W. Weller, The U. of Minnesota Press, Minneapolis, 1981, $146 \mathrm{pp}$.

[2] Wetland Functions and Values: The State of Our Understanding. American Water Resources Association, Minneapolis, MN, 1979, 674 pp.

[1] Freshwater Wetlands, R.E. Good, D. F. Whigham, and R. L. Simpson, eds.,Academic Press, New York, 1978, 378 pp. 